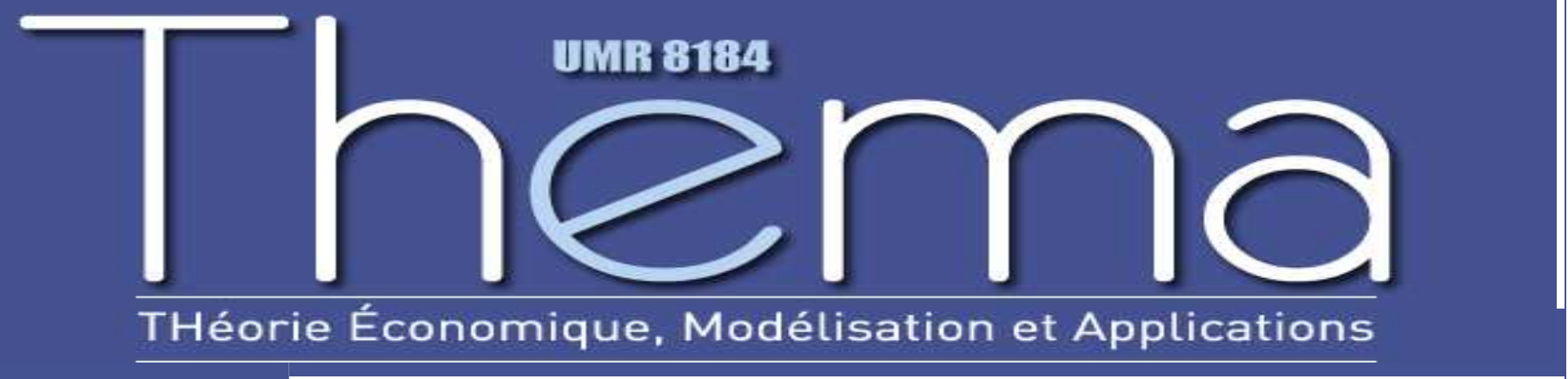

THEMA Working Paper n²016-06 Université de Cergy-Pontoise, France

\title{
Democratization and the Conditional Dynamics of Income Distribution
}

Michael T. Dorsch, Paul Maarek

May, 2016 


\title{
Democratization And the Conditional Dynamics of Income Distribution*
}

\author{
Michael T. Dorsch ${ }^{\dagger} \quad$ Paul Maarek ${ }^{\ddagger}$
}

May 28, 2016

\begin{abstract}
Most theoretical accounts imply that democratization will reduce income inequality as representative governments become accountable to citizens who would benefit from increased redistribution from the elite. Yet, available empirical evidence does not support the notion that democratization, on average, leads to more equal income distributions. This paper starts from the simple observation that autocracies are quite heterogeneous and govern extreme distributional outcomes (also egalitarian). From extreme initial conditions, democratization may lead income distributions to a "middle ground". We thus examine the extent to which initial inequality levels determine the path of distributional dynamics following democratization. Using fixed effects and instrumental variable estimates we demonstrate that egalitarian autocracies become more unequal following democratization, whereas democratization has an equalizing effect in highly unequal autocracies.
\end{abstract}

\footnotetext{
${ }^{*}$ We are grateful for the thoughtful comments of participants at the annual meeting of the European Public Choice Society (Freiburg).

${ }^{\dagger}$ Corresponding author. Central European University, Nádor u. 9, 1051 Budapest, Hungary; DorschM@.ceu.edu; +36 13273000 extension 2751.

${ }^{\ddagger}$ Université de Cergy-Pontoise, 33 boulevard du Port, 95011 Cergy-Pontoise Cedex, France; paul.maarek@u-cergy.fr.
} 


\section{Introduction}

This paper reconsiders the effect of democracy on the level of income inequality in society. We start from the simple observation that autocratic regimes are highly heterogeneous entities. From monarchistic, to business-friendly militaristic, to populistic, to communistic, autocratic regimes of the late 20th and early 21st centuries are almost defined by their competing ideologies concerning how spoils should be divided within the economies they govern. Indeed, the differences are not only ideological, but are reflected in the historical income inequality data - in our sample, autocratic countries have had Gini coefficients as low as 20 and as high as $75 .{ }^{1}$ If naturally follows that income inequality dynamics following transitions from autocracy to democracy may also be quite heterogeneous. This simple observation is our starting point, from which we provide thorough empirical documentation of a non-linearity that has not been examined in the literature. Namely, we demonstrate how income inequality dynamics following a switch to democracy depend on the initial (pre-democracy) level of income inequality. Intuitively, our results suggest that democracy provides a kind of "middle ground" - autocrats who governed extreme distributional outcomes are replaced by political processes that gravitate towards more centrist outcomes. More importantly, we provide evidence that democratization strongly affects the degree of income inequality despite the fact that the unconditional mean effect is null.

The most common narrative in the economics and political science literatures is that democratization should reduce inequality levels. Autocracies are often elite-dominated societies that have implemented political and economic institutions designed to protect the elite's wealth. Shifting to a democratic political institution allows for a broader set of economic interests to be served. In their canonical rational choice model of political transitions, Acemoglu and Robinson (2001) show how following the political enfranchisement of the poor, the decisive voter (or, decisive political preference) becomes relatively more poor and, all else equal, should call for inequality-reducing redistributions, following the classic rational theories of income taxation and redistribution (Meltzer and Richard 1981; Roberts 1977; Romer 1975). Moreover, the greater the initial degree of inequality before democracy, the greater should be the decline in inequality following a shift to democracy. ${ }^{2}$

Yet, the empirical literature concerning the effect of democracy on economic inequalities has not reached a consensus supporting this straightforward empirical prediction.

\footnotetext{
${ }^{1}$ Moreover, we later show that the heterogeneity in terms of income distribution is not driven by the economic development level. We show that the dispersion of Gini coefficients among autocratic countries is quite similar within income groups.

${ }^{2}$ See also Ansell and Samuels (2014) and Boix (2003) for alternative narratives from political science.
} 

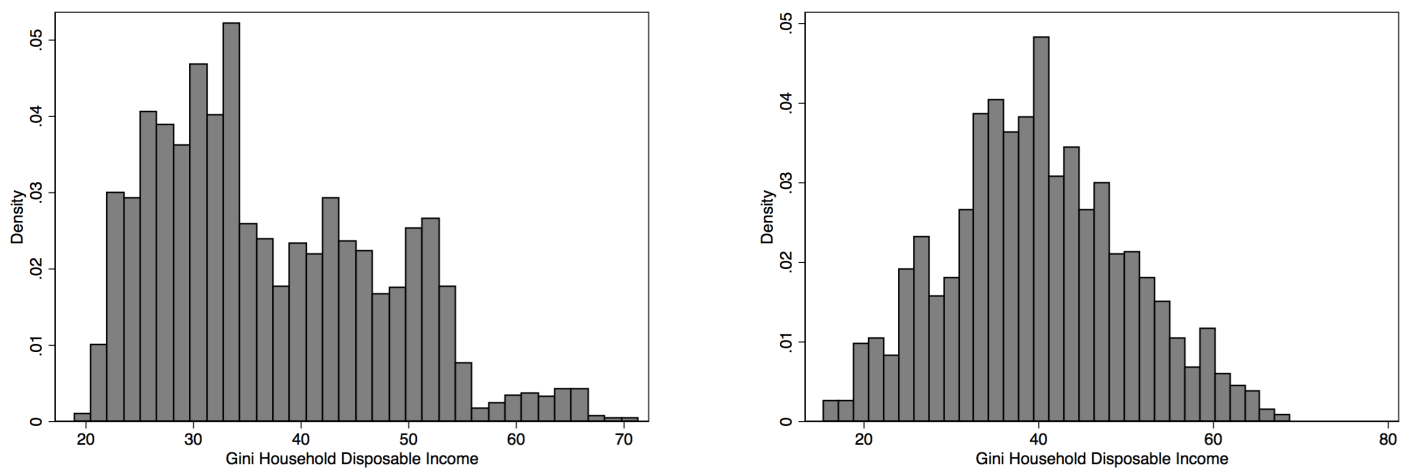

Figure 1: The distribution of Net Gini coefficients among autocracies (left) and democracies (right).

Acemoglu, Naidu, Restrepo, and Robinson (2015) carefully review this empirical literature, where results vary as widely as the methods employed and conclude that there is no clear evidence that inequality decreases following democratization. ${ }^{3}$ Employing fixed effects dynamic panel regression models, Acemoglu et al. (2015) go on to show that there is no robust statistically significant relation between switches to democracy and inequality levels. Such null results have led researchers to re-consider the extent to which the conflicts that drive democratization are distributive in nature (see, for example, Bidner et al. 2014 or Dorsch and Maarek 2015.)

However, the Acemoglu et al. (2015) study does not fully address the fact that autocracies are heterogeneous, a point made forcefully by Jones and Olken (2005), who demonstrate that economic performances of autocratic countries are highly leaderspecific (see also De Long and Shleifer 1993 and Reynolds 1985). Just as not all autocracies have histories of sclerotic growth, not all autocracies feature extreme income inequality. Figure 1 provides histograms of the net (after tax and transfer) Gini coefficient for autocracies and for democracies. Note that the tails of the distribution among autocracies are thicker, supporting the notion that autocratic countries govern relatively extreme income distributions. Table 1 provides some statistics concerning the distribution of net Gini coefficients across different per capita income ranges for autocratic and democratic countries. Note that the diversity among autocratic countries does not depend on the overall level of economic development.

\footnotetext{
${ }^{3}$ From case studies on 19th century Europe and 20th century Latin America (Acemoglu and Robinson, 2001), to cross sectional regressions (Gradstein and Milanovic, 2004; Mulligan et al., 2004; Perotti, 1996; Sirowy and Inkeles, 1990), to event histories (Aidt and Jensen, 2009), to sophisticated dynamic panel regressions (Acemoglu et al., 2015), the empirical literature has not established a convincing link between democratization and income inequality. For papers that investigate other proxies for inequality and/or redistribution, see also Rodrik (1999) Lindert (1994, 2004), Scheve and Stasavage (2009). See Lee (2005) for a study that highlights the importance of state capacity for the ability of new democracies to redistribute income.
} 
Autocratic countries are heterogeneous according to their income distributions for a variety of reasons. Historical differences in settler identities, institutional foundations, and types of agricultural cultivation shape differential inequality trajectories across autocracies, where structural inequalities may have been inherited from the past. Some autocratic countries are competently managed and have established good institutions that allow for equitable development, whereas others have not. Despite not having to stand for elections, autocratic regimes must cultivate political support from segments of the population in order to survive. Whether acting as a representative of the elite or of the downtrodden, autocratic rulers take ideological stances and redistributive policies to please their political "coalition" members that vary widely. As a result, also for political reasons, autocratic countries are heterogenous according to income distributions.

We follow the intuition established by Larsson-Seim and Parente (2013), who describe democracy as a middle ground on which formerly autocratic countries converge in terms of institutions and economic performances. We apply this intuition to modeling the dynamics of income inequality following a democratic switch. Extreme distributional outcomes that were politically sustainable under autocracy are unlikely to last once a switch to democracy occurs. Highly unequal autocracies are likely to see inequality reduced after democratization, when political institutions become more inclusive to the poorer segment of the population, which should pressure for more redistribution and pro-poor policies. On the contrary, highly equal autocracies are not likely to see inequality decrease after democratization since inequality was not a concern in those countries. In autocratic regimes that rely on a poor segment of the population for political support, unwinding a legacy of populist policies upon democratic liberalization creates opportunities for wealth creation that increases inequality levels.

Our basic point is that without taking into account how the effect is conditional on initial (pre-democracy) income levels, the contrasting experiences of switches to democracy in high and low inequality autocratic countries will cancel each other out, yielding the familiar null result, as in Acemoglu et al. (2015), for example.

We follow an empirical strategy that is broadly similar to Acemoglu et al. (2015): we employ fixed effects dynamic panel regression models to estimate the effect of switches to democracy as measured by an indicator that is constructed from three leading quantitative measures of democracy (following the example of Papaioannou and Siourounis 2008a). Our contribution beyond their study is two-fold. First, using the simple observation that autocratic countries are quite heterogeneous, we demonstrate that the 
impact of democratic switches conditional on initial levels of inequality is a robustly statistically significant determinant of income inequality dynamics. ${ }^{4}$ We demonstrate that, on average, relatively egalitarian autocracies become more unequal following democratization, whereas democratization has an equalizing effect in the relatively unequal autocracies. Our finding that the effect of democracy on inequality is conditional on initial inequality levels rationalizes the mixed results in the literature, where the relationship has typically been estimated unconditionally. As a result, contrary to prior views, democracy actually strongly affects the degree of inequalities. Second, we pursue an instrumental variable strategy for democratic switches that allows us to argue that the effect can be interpreted causally. Acemoglu, Naidu, Restrepo, and Robinson (2014) calculate, roughly speaking, the dynamic regional share of countries that are democratic as an instrument for democracy in their study that estimates how democratization affects growth. We construct a similar "democratic wave" instrument for our Two Stage Least Squares [2SLS] analysis, which confirms the importance of investigating the impact of democratization conditional on initial levels of inequality. Interacting the regional share democracy instrument with pre-democracy inequality levels gives us a strong and arguably exogenous set of instruments and we show that the instrumented conditional effect of a democratic switch is quite similar in magnitude to that from the simple OLS estimations. Ours is the first study to investigate the effect of democracy on inequality using a valid instrument for democratic change. We pursue a wide range of alternative specifications to demonstrate the robustness of our results. Among those exercises, we present results from 2SLS estimations that also instrument for initial (pre-democracy) inequality levels.

We then reflect on the possible mechanisms. Democratic switches occur for a multitude of reasons. When highly unequal, elite-dominated autocracies become democratic and political power is shifted to the middle, inequality gets reduced through redistribution and pro-poor policies (in line with Meltzer and Richard 1981; Roberts 1977; Romer 1975). However, more recent theoretical work in economics has suggested that the democratization process may not be about redistribution at all (Bidner et al., 2014; Dorsch and Maarek, 2015), and there is some empirical evidence to that effect (Aidt and Jensen, 2009; Haggard and Kaufman, 2012; Knutsen and Wegmann, 2016). Indeed, for formerly communist or collectivist autocracies, democratization was accompanied by market liberalizations and greater economic competition that may have increased inequalities from low initial levels. Autocratic societies are highly heterogeneous and

\footnotetext{
${ }^{4}$ Similar to the empirical literature on macro-economic convergence, we demonstrate how the dynamics of inequality following a switch to democracy depends on the initial (pre-democracy) level of income inequality.
} 
regression analyses that do not take this into account are ignoring important nonlinearities in the effect of democracy on income inequality.

The paper proceeds as follows. In the next section we describe the variables of interest and the data used for the analysis. The third section provides the details of our empirical strategy and results. In the fourth section, we discuss some mechanisms that may be behind our findings, while the final section concludes briefly.

\section{Data}

To investigate the extent to which democratization decreases (or increases) inequality levels, we gathered data from a variety of sources and constructed a country-level panel from 1960 - 2010. We begin by analyzing the yearly panels, but later in the paper we also analyze five-year panels.

Democratic political institution indicator. We construct binary indicators for the political system that follow Papaioannou and Siourounis (2008a) and later Acemoglu et al. $(2015,2014)$, in that we use several governance indicators to code our binary democracy variable. We combines the composite Polity2 index of the Polity IV dataset (Marshall et al., 2010) with the political freedom and civil liberties indexes of Freedom House (2013). ${ }^{5}$ Specifically, we consider a state as democratic when Freedom House codes it as "Free" or "Partially Free" and the Polity 2 index is positive. When one of those two criteria is not satisfied, the state is considered as autocratic. When one of the two criteria is satisfied but the other one is missing, we verify if the country is also coded as democratic by the binary indicator developed by Cheibub et al. (2010). ${ }^{6}$ Combining these three leading indicators allows us to address the issue of measurement error that the democracy indices may suffer from individually. The democracy indicator $\left[D(0,1)_{i, t}\right]$ takes value zero if country $i$ is determined to be autocratic in period $t$ and

\footnotetext{
${ }^{5}$ The Polity index codes the quality of democratic institutions by observation of, among other things, the competitiveness of political participation, the openness and competitiveness of choosing executives, and the constraints on the chief executive. The composite Polity index ranges from -10 to 10 , where -10 represents a fully autocratic political system and 10 represents a fully competitive democratic political institution. The Freedom House data measures political rights and civil liberties, both measured on a scale of 1 (most free) to 7 (least free). Political rights include free participation in the political process, including the right to vote for distinct alternatives in political elections, complete for public office, join parties or other political organizations, and elect representatives who actually have an impact on policy choices. Civil liberties include freedom of expression and belief, the right to join associations or organizations, protection under the rule of law, and personal autonomy from the state.

${ }^{6}$ We have directly followed the methodology developed by Papaioannou and Siourounis (2008a) and later applied by Acemoglu et al. (2014). See those papers for a more detailed description of the methodology.
} 
it takes value one if country $i$ is determined to be democratic in period $t .{ }^{7}$ Our results are robust to different thresholds for the indices we use and to more simple criteria for considering a country as democratic.

Both the political science and the economics literatures point to the possibility that democratization may be endogenously determined in this relationship, however. The multitude of papers that use variation in lagged income inequality to explain democratic transitions (though without consistent results), alerts us to the possibility that trends in inequality may be sufficiently persistent that even future inequality dynamics are influencing contemporaneous transitions to democracy. ${ }^{8}$ As such, we also pursue an instrumental variable strategy that isolates variation in our democracy indicator that is arguably exogenous to the dynamics of national income distributions. We follow the strategy of Acemoglu et al. (2014) and employ an instrument that relies on the observation that political transitions have historically occurred in regional "waves" ${ }^{9}$ by calculating the evolution of the fraction of countries with democratic institutions in a region among countries that shared the same political institutions at the beginning of the period.

Beyond addressing the possible reverse causality bias caused by any simultaneous determination, employing an instrument for democratization seems prudent for the following reasons. First, it allows us to deal with any time-varying omitted variables for which our baseline fixed-effects dynamic panel cannot fully control. Second, despite the fact that our democracy indicator is composed of several indicators, measurement error on marginal country-year cases remains a serious concern. To the extent that it is a strong first-stage predictor of democratization events, our instrument based on dynamic regional share of democracy smooths out the estimated impact of erroneously coded transitions.

\footnotetext{
${ }^{7}$ Note that we code both permanent and transitory transitions to democracy, and reversals to nondemocracy. Nothing indicates that the dynamics of inequality should be different in a democracy that eventually reverses to autocracy and democracy fully consolidated. Our measure of democracy captures a bundle of institutions that characterize electoral democracies. The indexes we use to construct our democracy variable include free and competitive elections, checks on executive power, and an inclusive political process that permits various groups of society to be represented politically. Our measure of democracy also incorporates the expansion of civil rights through the Freedom House's index. Acemoglu et al. (2014) show that these institutional components are quite strongly correlated.

${ }^{8}$ See, for example, Acemoglu and Robinson (2001, 2006); Acemoglu et al. (2015); Ansell and Samuels (2014); Boix (2003); Dorsch and Maarek (2014a,b); Freeman and Quinn (2012); Gassebner et al. (2013); Gradstein and Milanovic (2004); Haggard and Kaufman (2012); Houle (2009); Papaioannou and Siourounis (2008b).

${ }^{9}$ See Huntington (1993) for the classic exposition. In the modern economics literature, see, for example, Ellis and Fender (2011) and Dorsch and Maarek (2015) for theory and Aidt and Jensen (2014) or Persson and Tabellini (2009) for evidence. Though democracies have not been consolidated following the Arab Spring, the successive political transitions from autocracy also provides credence to the notion.
} 
More formally, we construct the following instrument for democratization events in country $i$ of region $r$ in period $t$, which we denote by $Z_{i, t}^{r}$ :

$$
Z_{i, t}^{r}=\frac{1}{N_{i, 0}^{r}-1} \sum_{j \in r, D_{j, 0}=D_{i, 0}, j \neq i} D_{j, t}
$$

where $N_{i, 0}^{r}$ corresponds to the number of countries in the region of country $i$ with the same institution as country $i$ at the beginning of the panel $\left(D_{j, 0}=D_{i, 0}\right)$. For a country $i$ we sum the number of countries sharing $i$ 's initial type of political institution $(j \neq i$, $\left.j \in N_{i, 0}^{r}\right)$ in the region $r$ that are democratic at time $t\left(D_{j, t}\right)$ excluding country $i$. The idea is to observe the evolution of democratic institutions in the countries in the same region as country $i$ which share the same institution initially. For instance, in a region in which initially 10 countries were autocratic, when considering one of them (country $i$ ), we look at the evolution of our democracy indicator in the 9 others in order to explain changes in country $i$. Intuitively, we expect what happens in the regional countries is not related to the degree of inequality in the domestic country $i$, except through its influence on domestic political institutions. ${ }^{10}$ When a "wave" of democratization reaches a region that was initially autocratic, this increases the probability that country $i$ democratizes. Figure 5 plots the country-specific instrument for six example countries from three different regions.

We have strong theoretical priors that such an instrument would be highly relevant and indeed, we later report some first-stage F-statistics well over 100. Logically, the instrument also seems quite likely to satisfy the exclusion restriction as national income distributions should not necessarily be affected by variation in regional political institutions other than through its effect on domestic political institutions. One limit of our instrument may be the fact that transitions in neighbor countries may affect growth there, which could affect growth in country $i$ if the regional economies are somewhat integrated and affect both inequality and the probability to observe a transition in country $i$. Growth may, for instance, affect the probability of democratization through the opportunity cost channel à la Acemoglu and Robinson (2001). There exists some empirical evidence for such an effect (see, for instance, Brückner and Ciccone 2011 or Burke and Leigh 2010). Growth may also affect inequality through the hypothesized "Kuznets curve" relation (Kuznets, 1955), though empirical evidence of such a relation is mixed. We thus control for the log of real GDP per capita in every specification of our paper. For the OLS specifications, it is a routine and obvious control. For the

\footnotetext{
${ }^{10}$ We classify countries into the following ten regions: (1.) Eastern Europe and post Soviet Union, (2.) Latin America, (3.) North Africa and Middle East, (4.) Sub-Saharan Africa, (5.) Western Europe and North America, (6.) East Asia, (7.) South-East Asia, (8.) South Asia, (9.) The Pacific, and (10.) The Caribbean.
} 
IV specifications, controlling for economic growth should help to satisfy the exclusion restrictions due to the indirect effect of democratization in neighboring countries on economic growth.

Regional countries may also share some common structural characteristics that may simultaneously affect political institutions and inequality, but all of our regressions include country fixed effects to capture those common features. Once conditioning the effect of the democracy instrument on within-country lags of inequality and economic growth, as well as period and country fixed effects, our set of excluded instruments should not have a direct effect on future period inequality in country $i$. Indeed, the results presented in the next section consistently fail to reject the null hypothesis that the set of instruments excluded from the second stage regressions are exogenous. Though not strictly accurate, we refer to the instrument for democracy as the "dynamic regional share of democracies" for simplicity.

Income inequality. For the inequality data, our benchmark specifications report results using the most standard measure of income inequality, the Gini coefficient. The Gini coefficient is a normalized measure between 0 and 100, where higher levels indicate a more unequal income distribution. We employ the Standardized World Inequality Indicators Database [SWIID], introduced by Solt (2009). The SWIID combines the Luxembourg Income Study with the World Inequality Indicators Database and standardizes the measurements across the two databases yielding a cross-national panel that is significantly enlarged from the individual databases. The Solt database also reports Gini coefficients for both the net income distribution (after taxes and transfers) and the gross income distribution. Throughout, we report results using both the net and the gross Gini coefficients, as democratization could both affect inequality due to direct redistribution or, more generally, transformation of institutions that may redistribute economic power in the population. As inequality levels may be path dependent and change rather slowly over time, in most specifications we also include lagged dependent variables to take into account the dynamics of inequality that may be independent of democratization events.

We are interested in observing how democratization events affect future inequality levels. We have hypothesized that the level of inequality before democratization will shape the direction of the relationship. In order to capture this conditional effect of democracy on inequality, we add an interaction between our democratization variable and the degree of inequality in the country prior to democratization. We define a fixed pre-democracy inequality variable for these interactions. Note that the level of inequality in the year of the democratic switch may not accurately reflect the level of inequality prevailing in autocracy since, for example, the regime may have made concessions 

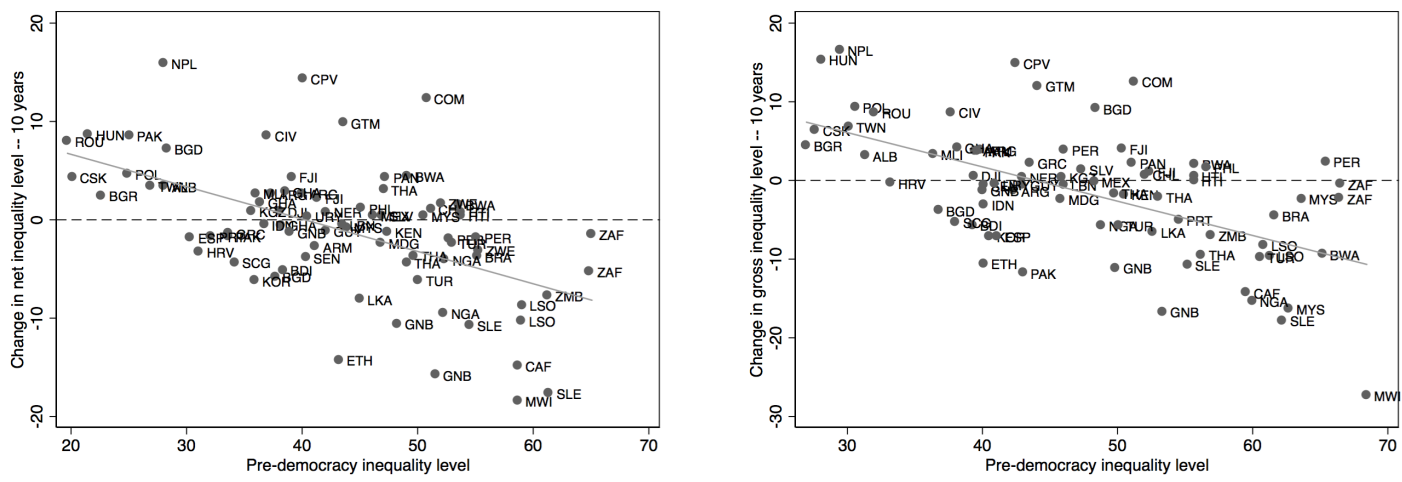

Figure 2: For the left-hand side, $\Delta$ Net Gini $=13.24^{* * *}-0.33^{* * *} \times \overline{\text { Gini }} \mathrm{R}^{2}=0.292$. For the right-hand side, $\Delta$ Gross Gini $=19.17^{* * *}-0.44^{* * *} \times \overline{\text { Gini. }} \mathrm{R}^{2}=0.333$.

through redistribution before being forced to democratize in the spirit of Acemoglu and Robinson (2001). Therefore, whenever possible, we take as the pre-democracy level of inequality the level of inequality prevailing five years before democratization occurs. When not available, we take the closest observation available for inequality to the five year window (for instance, four years before democratization occurs if the observation five years before is not available). We label this transition-specific variable as $\overline{\text { Gini }_{i}}$. In our robustness checks, we also consider some simpler codings of the pre-democracy inequality variable for use in the interaction term. Specifically, we alternatively define the fixed pre-democracy variable as the inequality level one year before the democratization and we also simply interact the democracy indicator with the time-varying Gini coefficient.

To provide further intuition for the battery of regression results that follow, we first consider several descriptive figures. We calculate the difference in the Gini coefficient ten years after a transition from its pre-democracy initial level. The left-hand side of figure 2 scatters this difference against the pre-democracy level for the net Gini coefficients $(\overline{\text { Gini }})$. The negative relationship is strongly statistically significant and the $\mathrm{R}^{2}$ is quite high for such a simple regression. The right-hand side of figure 2 is the analogue for the gross Gini coefficient, for which the correlation is even stronger. The figures show that 10 years after a switch to democracy, inequality increases in countries that were egalitarian autocracies and inequality decreases in countries that were unequal autocracies.

In the two-stage least squares estimations that instrument for democratization using the dynamic regional share of democracies, we also instrument for the interaction term by simply interacting the pre-democracy level of inequality $(\overline{\text { Gini }})$ with the dynamic regional share of democracies. In some regressions, we also instrument the initial degree 
of inequality using the instrument proposed by Easterly (2007). He finds (and we corroborate) that the abundance of land suitable for growing wheat relative to that suitable for growing sugarcane is strongly negatively correlated with the pre-democracy level of inequality in countries that have transitioned from autocracy to democracy over the period of our sample. The basic idea is that the land endowments suitable for growing commodities featuring economies of scale and the use of slave labor (sugar cane) is historically associated with high inequality. In contrast, commodities grown on family farms (typically wheat) promoted the growth of a large middle class and lower inequality levels.

Income per capita. Finally, in all regressions we have controlled for the lag of logged real GDP per capita, as measured by the Penn World Table (Heston et al., 2012). It is important to control for per capita income levels for two principle reasons. First, we take Lipset's Modernization Theory (Lipset, 1959) and the Kuznetz curve (Kuznets, 1955) seriously, so omitting per capita income would bias estimates of the effect of democracy, since both the likelihood of democracy and the evolution of income inequality may depend on economic development levels. Second, as mentioned above, controlling for per capita income makes us more confident that the democracy instrument satisfies the exclusion restriction. Summary statistics of all the variables used in the analysis are presented in table 2.

\section{Panel regression results}

This section presents the results of a series of panel regression models that highlight how the effect of democratization on inequality depends on initial (pre-democratization) levels of inequality. In our table of baseline results, we first present results from regressions where democratization and initial inequality are not interacted and then present a series of regressions that highlight how the effect of democratization significantly interacts

with initial inequality levels. The tables then go on to present analogous results using our external instruments for democratization. We have run all of the regressions on annual panels as well as on five-year panels. First, using the annual panels, we present our baseline tables that use as dependent variable the net Gini coefficient (table 3 ) and the gross Gini coefficient (table 4). Table 5 presents results that use simplified methods for calculating the initial (pre-democracy) inequality levels, table 6 considers several intuitive alternative samples, table 7 provides a series of 2SLS estimations that also instrument for the initial inequality level, and table 8 considers alternative democracy indicators. We then present the analogues of tables $3-7$ using five year panels in 
tables 9 - 13. Finally, table 14 provides results using GMM estimators for both the annual and the five-year panels. Though it is common in the empirical literature on political institutions to consider five-year panels, we prefer to focus attention on the annual panels due to the fact that our preferred specifications include lagged dependent variables and the so-called "Nickel bias" in dynamic panel regressions with fixed effects is less of a concern when there are many time periods in the panel (Nickel, 1981). All specifications control for the lag of logged per capita real national income, country fixed effects, and period fixed effects. In all tables, we report standard errors that have been clustered at the country level.

\subsection{Baseline regression analysis}

The first column of table 3 tests the extent to which democratization can explain within-country variation in inequality levels. Using ordinary least squares [OLS], we estimate:

$$
\operatorname{Gini}_{i, t}=\rho G i n i_{i, t-1}+\alpha D(0,1)_{i, t-1}+\beta G D P_{i, t-1}+\gamma_{i}+\delta_{t}+u_{i, t},
$$

where $D(0,1)_{i, t}=1$ is the indicator for democracy that was described above, the $\gamma_{i}$ 's denote a full set of country dummies that capture any time-invariant country characteristics that affect inequality levels, and the $\delta_{t}$ 's denote a full set of period dummies that capture common shocks to inequality levels. The error term $u_{i, t}$ captures all other factors not correlated with our controls which may also explain democratic improvements, with $E\left(u_{i, t}\right)=0$ for all $i$ and $t$. In general, in our estimations, the autoregressive effect is quite strong, suggesting that democratization takes time in order to produce sizable impacts on inequality. Thus, it is important that a dynamic estimator is employed. The second column allows for a stronger auto-regressive component to the estimated inequality dynamics by including four lagged dependent variables. The first two columns of table 3 demonstrate that the unconditional effect of lagged democratizations does not explain inequality levels with statistical significance. We also calculate the long-run effect on inequality levels of a switch to democracy as

$$
\frac{\hat{\alpha}}{1-\sum_{j=1}^{L} \hat{\rho}_{t-j}}
$$

where $L$ represents the number of lags on the dependent variable included in the specification.

The third and fourth columns of table 3 test the extent to which the effect of democratization is conditional on initial inequality levels using an interaction term 
between the democracy indicator and initial inequality levels. Formally, we estimate:

$$
\begin{aligned}
\operatorname{Gini}_{i, t}= & \rho G i n i_{i, t-1}+\alpha_{1} D(0,1)_{i, t-1}+\alpha_{2} D(0,1)_{i, t-1} \times \overline{G i n i}_{i} \\
& +\beta G D P_{i, t-1}+\gamma_{i}+\delta_{t}+u_{i, t} .
\end{aligned}
$$

Allowing for a conditional effect yields statistically significant estimates for the effect of democratization on inequality levels. For low initial levels of inequality a switch to democracy increases inequality, whereas for high initial levels of inequality democratization decreases inequality. When presenting estimation results that include the interaction term, we also report the p-value from an F-test of joint significance on the coefficients $\alpha_{1}$ and $\alpha_{2}$. Here as well, we calculate the long-run effect of a switch to democracy on inequality. But, note that the marginal effect of democratization when we include the interaction term is given by $\alpha_{1}+\alpha_{2} \times \overline{G i n i}_{i}$. For concreteness, we calculate the long-run effect at the 10th and 90th percentile inequality level (among autocratic countries, $\overline{\text { Gini }}^{10}=27.5$ and $\overline{\text { Gini }}^{90}=57$ ) as

$$
\frac{\hat{\alpha}_{1}+\hat{\alpha}_{2} \overline{G i n i}^{p c}}{1-\sum_{j=1}^{L} \hat{\rho}_{t-j}},
$$

where again $L$ indicates the number of lagged dependent variables we include in the specification. The regression estimates from column 3 imply that the long-run impact of a switch to democracy for a country in the 10th percentile of inequality is for the net Gini coefficient to increase by nearly 4 points. By contrast, the long-run impact for a country in the 90th percentile of inequality is for the Gini coefficient to decrease by more than 6 points. This simple estimation demonstrates how transitions to democracy, on average, bring extreme income distributions to some "middle ground".

Figure 3 provides a visualization of the conditional marginal effect estimated in column 3. The plotted line shows the marginal effect of a switch from $D_{i, t-2}=0$ to $D_{i, t-1}=1$ on inequality levels in period $t$ as a function of pre-democracy inequality levels. The plot is super-imposed over a histogram of the distribution of net Gini coefficients to provide a sense of the empirical relevance of the range of initial inequality levels for which the effect of a switch to democracy is statistically significant.

The next four columns of table 3 present results from a two-stage instrumental variable procedure (2SLS). We consider both the democracy indicator and its interaction term as potentially endogenous and instrument for both of them. Thus, the first stage equations we estimate are:

$$
\begin{aligned}
D(0,1)_{i, t} & =\alpha_{1} Z_{i, t}+\alpha_{2} Z_{i, t} \times \overline{G i n i}_{i}+\beta G D P_{i, t-1}+\gamma_{i}+\delta_{t}+e_{i, t} \text { and } \\
D(0,1)_{i, t} \times \overline{G i n i}_{i} & =\alpha_{1} Z_{i, t}+\alpha_{2} Z_{i, t} \times \overline{G i n i}_{i}+\beta G D P_{i, t-1}+\gamma_{i}+\delta_{t}+e_{i, t} .
\end{aligned}
$$




\section{Yearly panels}

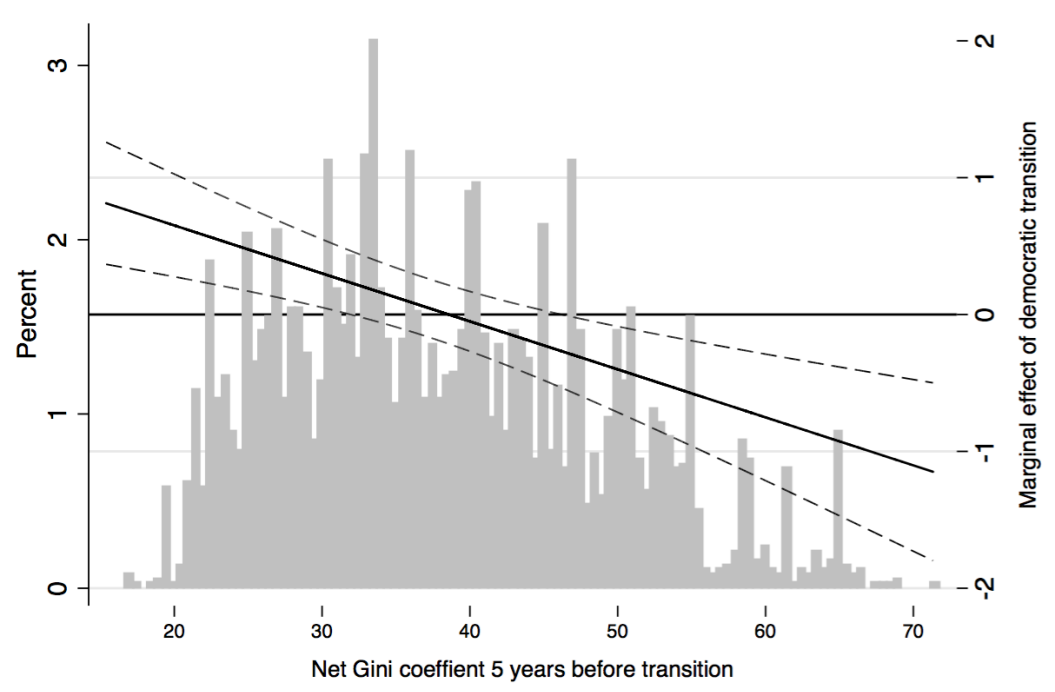

Figure 3: The marginal effect of a democratic transition on net Gini coefficients, conditional on the initial (pre-democracy) level of inequality. The figure is based on regression estimates from column (3) of table 3. Dashed lines represent $90 \%$ confidence intervals.

We use the fitted values from equations (5) in the second stage:

$$
\begin{aligned}
\operatorname{Gini}_{i, t}= & \rho G i n i_{i, t-1}+\alpha_{1}^{2 S} D\left(\widehat{0,1)_{i, t-1}}+\alpha_{2}^{2 S} D\left(0,1{\widehat{)_{i, t-1}} \times \overline{G i n i}_{i}}\right.\right. \\
& +\beta G D P_{i, t-1}+\gamma_{i}+\delta_{t}+u_{i, t} .
\end{aligned}
$$

Columns 5 and 6 include a single lagged dependent variable, while columns 7 and 8 include four. To save space, we present only the second stage results (though we report first-stage F-statistics as justification for the strength of the instruments). Columns 5 and 7 are exactly identified (the number of excluded instruments is the same as the number of endogenous variables). The specifications in columns 6 and 8 are over-identified, allowing us to report the Hanson p-values that test whether the set of excluded instruments can be considered exogenous. As an extra excluded instrument we also use the second lag of the share of a country's region that is democratically governed. In the next sub-section where we investigate the robustness of the baseline results, we also instrument for the pre-democracy Gini coefficient in the interaction term.

To conserve space, we do not report the unconditional effect of a switch to democracy (as in columns 1 and 2), but note that it is also insignificant when we use an instrument for democracy. However, conditional on initial levels of inequality, the effect is highly statistically significant (columns $5-8$ ). First-stage F-statistics indicate that the set of instruments is strong (well above rule of thumb 10). Recalling that the 
null hypothesis of the Hansen J-test is that the set of excluded instruments are exogenous, the p-values from the over-identified regressions (in column 6 and 8) confirm the validity of the set of instruments along this dimension. We also calculated the implied long-run impact of a switch to democracy and report similarly that democratization, on average, brings extreme income distributions towards a "middle ground." The estimates from column 5, for example, imply that a switch to democracy for an autocracy with an initial inequality level at the 10th (90th) percentile leads to a long-run increase by more than 6 points (decrease by nearly 7 points) of the Gini coefficient. Such movements correspond to a greater than $50 \%$ reduction in the gap between the 90th and 10th percentile inequality levels for countries that have switched to democracy.

The 2SLS estimates are quite close to the simple OLS estimates. The 2SLS estimates imply a larger increase in inequality for perviously egalitarian autocracies (when

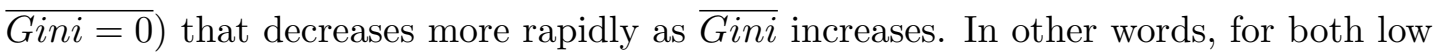
and high initial levels of inequality, OLS slightly underestimates the impact of a switch to democracy. Such an underestimate would be consistent with endogeneity concerns centered around the notion that autocrats might adjust their policies to try to prevent a democratization - redistribute in elite-dominated autocracies or liberalize some markets in collectivist autocracies.

\subsection{Robustness analysis}

This subsection briefly presents the various robustness checks that we have conducted. The results are generally robust to estimation with the alternative specifications that we describe below.

Market income inequality. In table 4, we use the gross Gini coefficient, rather than the net Gini coefficient, as reported in the previous table. The coefficient estimates are similar, though the calculated long-run effects have some interesting differences in the specifications with multiple lagged dependent variables. At the 90th percentile Gini, the calculated long-run decrease is larger for market inequality than for net inequality. At the 10th percentile Gini, the calculated long-run increase is larger for the net inequality than for the market inequality. This may indicate that the effect of democratization occurs through different channels. Evolving market opportunities following democratization, for example, may affect income distributions beyond the effect of the change in redistributive policies that the literature typically focuses upon.

Alternative pre-democracy inequality coding. In table 5, for transparency, we employ simpler constructions of the interaction term. In columns $1-4$, the predemocracy inequality variable is simply the level of inequality during the year of democratization, which we keep fixed for periods following the democratization. In columns 
$5-8$, we simply interact the democracy indicator with the raw Gini data, allowing it to change during the period of the democratic switch. Results are robust to these simplified coding schemes.

Restricted sample. Table 6 considers several intuitive sub-samples. First, columns $1-3$ drop countries that were officially part of the former Soviet Union. Columns 4 6 additionally drops the Central and Eastern European countries that were signatories of the Warsaw Pact. ${ }^{11}$ That the results are generally quite similar after dropping these groups of countries is quite encouraging. The non-linearity is not being driven by a particular group of countries, but the pattern appears to be more general. Finally, columns $7-9$ of table 6 drops countries that have never been autocratic over the length of the panel.

Instrumenting for pre-democracy inequality as well. In table 7 we also consider the possibility that the initial (pre-democracy) levels of inequality are endogenously determined. For example, even when using the most stringent coding for the initial level of inequality (five years before the switch to democracy), it's possible that autocrats use redistribution in attempt to prevent a democratic transition. Such an endogenous relationship would mean that our baseline results have over-estimated the conditional effect of democratic switches (even if we should partly prevent this using lagged values of inequalities much before transition occurs as our initial degree of inequality variable). Using the historical agricultural instrument proposed by Easterly (2007) for inequality, we can quite confidently eliminate the possible bias caused by such a strategic redistribution. Recalling that the instrument is the ratio of land suitable for growing wheat relative to sugarcane, $A_{-}$ratio $_{i}$ is strongly negatively correlated with $\overline{\text { Gini }}$ (initial pre-democracy inequality) in our sample. We interact the dynamic share democracy instrument with the $A g$ ratio to instrument the interaction term of interest. The first stage regressions are the following:

$$
\begin{aligned}
D(0,1)_{i, t} & =\alpha_{1} Z_{i, t}+\alpha_{2} Z_{i, t} \times \text { Ag_ratio }_{i}+\beta G D P_{i, t-1}+\gamma_{i}+\delta_{t}+e_{i, t} \text { and } \\
D(0,1)_{i, t} \times \overline{G i n i}_{i} & =\alpha_{1} Z_{i, t}+\alpha_{2} Z_{i, t} \times \text { Ag_ratio }_{i}+\beta G D P_{i, t-1}+\gamma_{i}+\delta_{t}+e_{i, t} .
\end{aligned}
$$

We use the fitted values from equations (8) in the second stage as before.

While the historical nature of the inequality instrument ensures that it satisfies the exclusion restriction, it comes at the cost of it's relevance for explaining modern

\footnotetext{
${ }^{11}$ While we do not have data for all of these countries, modern countries that were formerly part of the Soviet Union include Russia, Ukraine, Uzbekistan, Kazakhstan, Belarus, Azerbaijan, Georgia, Tajikistan, Moldova, Kyrgyzstan, Lithaunia, Turkmensitan, Armenia, Latvia, and Estonia. The original signatories to the Warsaw Treaty Organization were the Soviet Union, Albania, Poland, Czechoslovakia, Hungary, Bulgaria, Romania, and the German Democratic Republic.
} 
income inequality (especially net). Nevertheless, the results in table 7 are encouraging. In columns 1 and 2 Ag_ratio is used to instrument for the interaction term with our baseline coding for the initial inequality level, whereas in columns 3 and 4 it's used to instrument for the interaction with the simple coding. Unsurprisingly, the second stage estimate for the interaction effect is less precisely estimated using Ag_ratio as an instrument for $\overline{G i n i}$, but we note that the joint effect remains statistically significant. In columns $5-8$, we pursue a more "reduced form" specification in which we interact the Ag_ratio instrument directly with the democratic transition variable (as the potentially endogenous variable) and then instrument for it with the interaction of the regional share democracy with the Ag_ratio. More formally, the first stage regressions that we estimate for the second stage results shown in columns $5-8$ are the following:

$$
\begin{aligned}
& D(0,1)_{i, t}=\alpha_{1} Z_{i, t}+\alpha_{2} Z_{i, t} \times \text { Ag_ratio }_{i}+\beta G D P_{i, t-1}+\gamma_{i}+\delta_{t}+e_{i, t} \\
& D(0,1)_{i, t} \times A_{\text {g_ratio }}=\alpha_{1} Z_{i, t}+\alpha_{2} Z_{i, t} \times A_{\text {A_ratio }}+\beta G D P_{i, t-1}+\gamma_{i}+\delta_{t}+e_{i, t},
\end{aligned}
$$

Columns 5 and 6 show the second stage results when the net Gini is the dependent variable and columns 7 and 8 are the analogues for when we use the gross Gini coefficient as the dependent variable.

Alternative democracy indicator coding. In table 8, we consider several alternative coding specifications for the democracy indicator. In columns $1-4$, we continue to utilize the method of Papaioannou and Siourounis (2008a) and combine three different sources of information concerning the quality of democratic political institutions, but we employ more stringent criteria for coding a country-year observation as democratic. In the more stringent version used here, a country-year observation must achieve a Polity IV score of greater than 4 to be considered democratic. In the event that the Polity IV data is not available, the more stringent criteria does not come into effect. In columns 5-8, we employ a democracy indicator that uses only the Polity IV data. As is common, the indicator based only on the Polity IV defines a country-year observation as a democracy for positive values and as a non-democracy for non-positive values of the Polity IV index. Results are robust to both of these alternative codings for the democracy indicator.

\subsection{Regression analysis using five-year panels}

Tables $9-13$ are the analogues to tables $3-7$ using five-year panels. Starting from 1960 , we take the variables' values in the first year of each five-year panel. Variables that are lagged one period are thus lagged five years. Results are qualitatively consistent with those from the estimations using annual data, but estimates are somewhat 
Five year panels

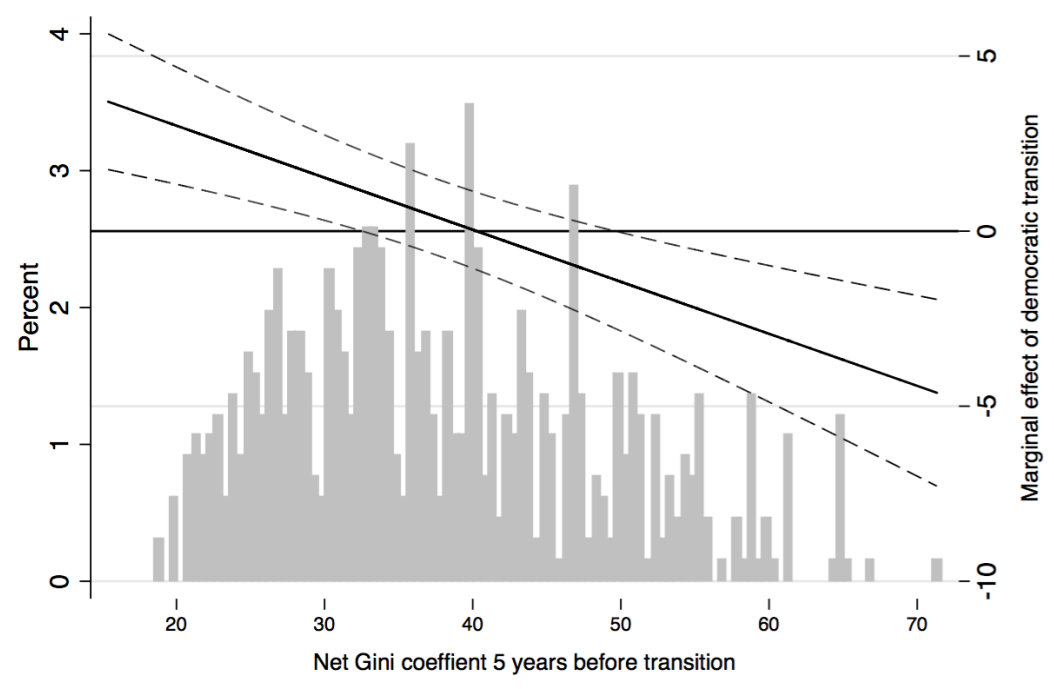

Figure 4: The marginal effect of a democratic transition on net Gini coefficients, conditional on the initial (pre-democracy) level of inequality. The figure is based on regression estimates from column (4) of table 9. Dashed lines represent $90 \%$ confidence intervals.

more volatile across the various specifications. Obviously, we are left with far fewer observations when using the five-year panels and the panel length for each country is shortened significantly. Nevertheless, the main themes from the annual panels hold up: (i) there is no statistically significant unconditional effect of democratic switches, (ii) the effect of democratic switches conditional on initial inequality levels is highly statistically significant (see figure 4), (iii) after a democratic switch inequality increases in countries that were initially egalitarian and inequality decreases in countries that were initially unequal, (iv) our proposed set of instruments is both relevant and exogenous and 2SLS regressions corroborate the OLS findings (though the OLS bias is larger when using the five-year panels), (v) the results are robust to using market data, to simpler constructions of pre-democracy inequality levels, and to intuitive sample restrictions, and (vi) results from a 2SLS procedure that also instruments for the initial level of inequality using the Easterly instrument are consistent with those from the baseline specification.

\subsection{GMM regressions}

Finally, since fixed effects regression estimates can be biased by the inclusion of lagged dependent variables (Nickel, 1981), in table 14 we consider estimation of our baseline specification with a standard generalized method of moments (GMM) estimator along 
the lines of Arellano and Bond (1991), rather than with fixed effects OLS regressions. The table presents our baseline specification using both annual and five year panels, using both net and gross income inequality measures, estimated using the Arellano-Bond GMM estimator. Following Acemoglu et al. (2015), we include the lagged dependent variable as a control, remove country fixed effects by taking forward orthogonal differences, collapse the number of lags used as instruments, and report the $\mathrm{AR}(2)$ p-value. Our main result is robust to this alternative estimation technique.

\section{Discussion}

\subsection{Possible mechanisms}

In this section, we briefly discuss several possible mechanisms that could be driving the conditional income inequality dynamics that we have empirically documented. The first relates to the economic institutional change that accompanies political transitions to democracy, which could plausibly contribute to increases or decreases in inequality levels. The second relates to the shift in political representation towards the preferences of the "median voter". Third, we note that democratization is often associated with structural economic transitions out of agricultural production that may increase inequality levels. Finally, we observe that inequality may have very historically deep roots that autocratic governments may not attempt to reverse. On net, the mechanisms through which democratization may affect the distribution of income do not operate uniformly, and indicate why unconditional tests of the effect have usually turned up null results. Empirically teasing out which mechanism is the most relevant and has the strongest impact on our middle ground result is beyond the scope of the present paper, however.

First of all, transitions to democratic political institutions involve institutional changes that transcend the political, including those that govern economic, educational, and public health systems. Generally speaking, reforms to these areas of public life could have either equalizing or polarizing effects on income distributions. First, liberalizing political institutions often leads to liberalizing economic reforms that make economies more competitive through, for example, the removal of barriers to entry (De Haan and Sturm, 2003; Djankov et al., 2002; Fidrmuc, 2003; Méon and Sekkat, 2016; Rode and Gwartney, 2012). Increased entrepreneurial opportunities may allow for some new high incomes to be created, increasing inequality. Indeed, Dorsch and Maarek 
(2015) provide a theory of political transitions in which removal of such opportunitysuppressing barriers to entry may be the institutional grievance that prompts a democratic concession by the elite. ${ }^{12}$ Additionally, democracies tend to invest more in the productive capacity of their populations through greater provision of public goods as well as increased and more broadly spread education and health care (Acemoglu et al., $2005,2015)$. The net effect of greater public investment on inequality levels could go either way.

Second, upon democratization, leaders must establish broader coalitions of political support than those necessary to maintain power in an autocracy (Bueno de Mesquita et al., 2003). Many autocrats establish small coalitions of intense support in the extremes of the income distribution, with populist regimes courting the poor and elitist regimes courting the rich (Acemoglu et al., 2004). Which subgroups a leader forms coalitions with may depend on many factors, such as the cost of revolt and/or suppression, geography and the quality of infrastructure, the country's military tradition, etc. Autocratic leaders cultivate political coalitions according to the relative power of the subgroups in society and form extreme policies to benefit their coalition of support. Extreme policy positions yield (or protect) extreme distributional outcomes, from highly equal communistic regimes to highly unequal elite-dominated regimes. Democratic governance is more inclusive and political leaders must establish broader coalitions which naturally expand to the middle. Thus, in practice, the critical member of the minimum winning coalition in a democracy is likely to be more central in the distribution of policy preferences than previously. If policy preferences are monotonic in income level, the center of the policy preference distribution corresponds to the center of the income distribution. As such, for both highly unequal and egalitarian autocracies, the distributional policy is likely to move to a middle ground following democratization, reducing inequalities in the elite-dominated societies and increasing inequality in the communistic societies.

Third, democratization may be associated with structural economic changes. For agricultural societies, democratization may induce industrialization and urbanization. As worker productivity and wages increase as the economy industrializes, many former peasants are brought out of poverty. As industrial production has more unequal incomes than agricultural production, a structural shift towards industrial production should lead to higher income inequality. This is the main argument Kuznets (1955) uses to explain why development affects economic inequality. In autocracies, independent of the level of economic development (which induces structural transformation and for

\footnotetext{
${ }^{12}$ Though they do not explicitly derive the impact of democratization on income inequality, in their model, democratization that removes barriers to entry would increase the level of inequality in society.
} 
which we control in the regressions), the elite may block the introduction of new modern technologies of production (which would induce structural change if implemented) in order to keep rents in sectors they operate. In line with such theories, Acemoglu et al. (2014) show that democratization fosters structural change through the development of industry. This effect (and the subsequent impact on income inequalities) could be strong in countries in which the elite dominated some sectors.

Finally, politics in autocracies may have had nothing do with the level of income inequality and don't pursue policies to modify them. Inequality may simply have deep historical roots (Easterly, 2007) and following a transition to democracy, politicians will engage in redistribution and specific policies for reducing inequalities only in countries in which inequalities are high and there exists some margin to redistribute.

\subsection{Comparison with related literature}

The paper is most closely related to Acemoglu et al. (2015), who also investigate the effect of democracy on levels of inequality. The literature review found there convincingly documents that there is no empirical consensus concerning the effect of democracy on inequality levels. Using fixed effects panel regression techniques, Acemoglu et al. (2015) find mainly null results in tests of the unconditional correlation between democracy and inequality.

Acemoglu et al. (2015), however, include some specifications which allow for democracy to have heterogeneous effects according to land inequality, share of agriculture in the economy, as well as top and bottom decile income shares. They find evidence that countries where land is more unequally distributed see income inequality increase upon democratization, which they describe as providing evidence for elite capture of new democracies. If land inequality and (pre-democracy) income inequality are inversely related, then this result is consistent with our results.

They also find evidence that highly agricultural economies become more unequal after democracy, which they describe in terms of the increased market opportunities that are available outside of agriculture following a switch to democracy. Again, to the extent that highly agricultural economies are those with low levels of (pre-democracy) inequality, then this is consistent with the results that we have presented.

However, they find no consistent evidence that bottom or top decile income shares shape post-democratization income inequality dynamics. While Acemoglu et al. (2015) do consider several interesting heterogeneous responses to democratic switches, our paper complements their results substantially. The conditional effect that we have investigated is more general and rests on the intuition that democracy provides a 
middle ground on which societies with relatively extreme income distributions can converge. Our results clearly indicate that the effect is conditional on initial levels of inequality, and not a more general process of economic development following democratization. Furthermore, we have pursued an instrumental variables strategy and demonstrated that the conditional effect of democracy on income inequality can be interpreted causally.

Even though our paper has considered the effect of democratization on inequality levels, it is also relevant for the literature on the causes of democratization. The canonical rational choice model of democratization (Acemoglu and Robinson, 2001, 2006) supposes that democratically-determined fiscal redistribution follows the logic established by Meltzer and Richard (1981), Roberts (1977), and Romer (1975), where democracies with greater inequality redistribute more. In the democratization model, higher inequalities are associated with a higher probability of a transition to democracy, as the greater potential for democratic fiscal redistribution increases the revolutionary threat. ${ }^{13}$ The empirical literature that examines this relationship has also found largely null results (see, for example, Houle 2009 and Teorell 2010 and the references therein), but the tests are generally on the unconditional effect of inequality. Some scholars have questioned whether inequality and redistribution are actually important for democracy and transitions towards it (Knutsen and Wegmann 2016, for example). Our results show that critiques of the logic established by the canonical rational choice model of democratization based on the available empirical evidence are perhaps not convincing. We have demonstrated that inequality does fall following democratization in countries where inequality was very high. Therefore, high inequality levels can be a source of tension that drives democratization, but it's not a general pattern because some autocracies are quite egalitarian with little to redistribute.

\section{Concluding remarks}

There is no consensus in the empirical literature about whether or not autocracies that democratize become more egalitarian. We propose that the reason for this is that autocracies are highly heterogeneous, especially with respect to how incomes are distributed. Intuitively, autocracies allow for extreme policy outcomes that might not be possible in democratically governed societies, where policy choices should follow more closely the preferences in the middle of the distribution of preferences. Allowing for the effect of democracy to be conditional on pre-democracy inequality levels, we

\footnotetext{
${ }^{13}$ Technically, the theory predicts an inverted U relationship, as if the redistribution under democratic fiscal policy is anticipated to be too great, then the elite will fight to prevent it.
} 
demonstrate a robustly statistically significant conditional effect of democratization on inequality levels. Highly unequal autocracies become more equal following switches to democracy, whereas egalitarian autocracies become less equal following switches to democracy. In sum, democratization has a strong impact on inequality levels, but the effect pushes in opposite directions depending on prevailing levels of inequality prior to the switch to democracy, which rationalizes the typical null result found in the literature. An instrumental variable analysis suggests that the effect of democracy on income inequality can be interpreted causally.

The objective of our paper was mainly to explain the counter-intuitive null result found in the literature and demonstrate that democratic transitions are not at all neutral events in terms of the dynamics of income inequality. The basic observation with which we began the paper, that autocracies are very heterogeneous according to inequality levels, provides an interesting starting point for further future research. We

have briefly discussed some intuition for these heterogeneities and for the converging dynamics that democratization sets off, but a full characterization of those mechanisms is an important research program for the future.

\section{References}

Acemoglu, D., Johnson, S., Robinson, J. A., 2005. From education to democracy? The American Economic Review 95 (2), 44-49.

Acemoglu, D., Naidu, S., Restrepo, P., Robinson, J., 2014. Democracy does cause growth. NBER Working Paper 20004.

Acemoglu, D., Naidu, S., Restrepo, P., Robinson, J. A., 2015. Democracy, redistribution, and inequality. In: Atkinson, A. B., Bourguignon, F. (Eds.), Handbook of Income Distribution. Elsevier, pp. 1885 - 1966.

Acemoglu, D., Robinson, J., 2001. A theory of political transitions. American Economic Review 91 (4), 938-963.

Acemoglu, D., Robinson, J., 2006. The Economic Origins of Dictatorship and Democracy. Cambridge University Press, New York.

Acemoglu, D., Verdier, T., Robinson, J. A., 2004. Kleptocracy and divide-and-rule: A model of personal rule. Journal of the European Economic Association 2 (2-3), $162-192$.

Aidt, T. S., Jensen, P. S., 2009. The taxman tools up: An event history study of the introduction of the personal income tax. Journal of Public Economics 93 (1), 160-175. 
Aidt, T. S., Jensen, P. S., 2014. Workers of the world unite! Franchise extensions and the threat of revolution in Europe, 1820-1938. European Economic Review 72, 52-75.

Ansell, B. W., Samuels, D. J., 2014. Inequality and Democratization: An Elite Competition Approach. Cambridge University Press, Cambridge, UK.

Arellano, M., Bond, S., 1991. Some specification tests for panel data: Monte Carlo evidence and an application to employment equations. Review of Economic Studies 58 (2), 277-298.

Bidner, C., Francois, P., Trebbi, F., 2014. A theory of minimalist democracy. NBER Working Paper 20552.

Boix, C., 2003. Democracy and Redistribution. Cambridge University Press, New York.

Brückner, M., Ciccone, A., 2011. Rain and the democratic window of opportunity. Econometrica 79 (3), 923-947.

Bueno de Mesquita, B., Smith, A., Siverson, R., Morrow, J., 2003. The Logic of Political Survival. MIT Press, Cambridge.

Burke, P., Leigh, A., 2010. Do output contractions trigger democratic change? American Economic Journal: Macroeconomics 2, $124-157$.

Cheibub, J., Gandhi, A., Vreeland, J., 2010. Democracy and dictatorship revisited. Public Choice 143 (1-2), 67-101.

De Haan, J., Sturm, J.-E., 2003. Does more democracy lead to greater economic freedom? New evidence for developing countries. European Journal of Political Economy $19(3), 547-563$.

De Long, J. B., Shleifer, A., 1993. Princes and merchants: European city growth before the industrial revolution. Journal of Law and Economics 36 (3), 2.

Djankov, S., La Porta, R., Lopez-De-Silanes, F., Shleifer, A., 2002. The regulation of entry. Quarterly Journal of Economics 117 (1), 1-37.

Dorsch, M., Maarek, P., 2014a. Economic downturns, inequality, and democratic improvements. THEMA Working Paper 2014-19.

Dorsch, M., Maarek, P., 2014b. A note on economic inequality and democratization. Peace Economics, Peace Science \& Public Policy 20, 599-610.

Dorsch, M., Maarek, P., 2015. Inefficient predation and political transitions. European Journal of Political Economy 37, 37-48. 
Easterly, W., 2007. Inequality does cause underdevelopment: Insights from a new instrument. Journal of Development Economics 84, 755-776.

Ellis, C., Fender, J., 2011. Information cascades and revolutionary regime transitions. The Economic Journal 121, 763-792.

Fidrmuc, J., 2003. Economic reform, democracy and growth during post-communist transition. European Journal of Political Economy 19 (3), 583-604.

Freedom House, 2013. Freedom of the World and Freedom of the Press. published online.

Freeman, J., Quinn, D., 2012. The economic origins of democracy reconsidered. American Political Science Review 106 (1), 58-80.

Gassebner, M., Lamla, M., Vreeland, J., 2013. Extreme bounds of democracy. Journal of Conflict Resolution 57 (2), 171-197.

Gradstein, M., Milanovic, B., 2004. Does liberté= égalité? A survey of the empirical links between democracy and inequality with some evidence on the transition economies. Journal of Economic Surveys 18 (4), 515-537.

Haggard, S., Kaufman, R. R., 2012. Inequality and regime change: Democratic transitions and the stability of democratic rule. American Political Science Review 106 (3), $495-516$.

Heston, A., Sumers, R., Aten, B., 2012. Penn World Table, version 7.1. Center for International Comparisons of Production, Income and Prices, University of Pennsylvania, Philadelphia.

Houle, C., 2009. Inequality and democracy: Why inequality harms consolidation but does not affect democratization. World Politics 61 (4), 589-622.

Huntington, S. P., 1993. The Third Wave: Democratization in the Late Twentieth Century. Vol. 4. University of Oklahoma Press.

Jones, B. F., Olken, B. A., 2005. Do leaders matter? National leadership and growth since World War II. The Quarterly Journal of Economics, 835-864.

Knutsen, C. H., Wegmann, S., 2016. Is democracy about redistribution? Democratization $23,164-192$.

Kuznets, S., 1955. Economic growth and income inequality. The American Economic Review 45 (1), 1-28. 
Larsson-Seim, A., Parente, S. L., 2013. Democracy as a middle ground: A unified theory of development and political regimes. European Economic Review 64, 35-56.

Lee, C.-S., 2005. Income inequality, democracy, and public sector size. American Sociological Review 70 (1), 158-181.

Lindert, P. H., 1994. The rise of social spending, 1880-1930. Explorations in Economic History 31 (1), 1-37.

Lindert, P. H., 2004. Social Spending and Economic Growth Since the Eighteenth Century. Cambridge University Press.

Lipset, S., 1959. Some social requisites of democracy: Economic development and political legitimacy. American Political Science Review 53, 69-105.

Marshall, M., Jaggers, K., Gurr, T., 2010. Polity IV Project: Dataset Users' Manual. Center for Systemic Peace, Arlington.

Meltzer, A. H., Richard, S. F., 1981. A rational theory of the size of government. Journal of Political Economy 89, 914-927.

Méon, P.-G., Sekkat, K., 2016. A time to throw stones, a time to reap: How long does it take for democratic transitions to improve institutional outcomes? CEB Working Paper N. 16/016.

Mulligan, C., Gil, R., Sala-i Martin, X., 2004. Do democracies have different public policies than nondemocracies? Journal of Economic Perspectives 18 (1), 51-74.

Nickel, S., 1981. Biases in dynamic models with fixed effects. Econometrica 49, $1417-$ 1426.

Papaioannou, E., Siourounis, G., 2008a. Democratization and growth. The Economic Journal 118 (532), 1520-1551.

Papaioannou, E., Siourounis, G., 2008b. Economic and social factors driving the third wave of democratization. Journal of Comparative Economics 36 (3), 365-387.

Perotti, R., 1996. Growth, income distribution, and democracy: What the data say. Journal of Economic Growth 1 (2), 149-187.

Persson, T., Tabellini, G., 2009. Democratic capital: The nexus of political and economic change. American Economic Journal: Macroeconomics, 88-126.

Reynolds, L. G., 1985. Economic growth in the third world, 1850-1980. 
Roberts, K. W., 1977. Voting over income tax schedules. Journal of Public Economics $8(3), 329-340$.

Rode, M., Gwartney, J., 2012. Does democratization facilitate economic liberalization? European Journal of Political Economy 28, 607-619.

Rodrik, D., 1999. Democracies pay higher wages. Quarterly Journal of Economics $114(3)$.

Romer, T., 1975. Individual welfare, majority voting, and the properties of a linear income tax. Journal of Public Economics 4 (2), 163-185.

Scheve, K., Stasavage, D., 2009. Institutions, partisanship, and inequality in the long run. World Politics 61 (02), 215-253.

Sirowy, L., Inkeles, A., 1990. The effects of democracy on economic growth and inequality: A review. Studies in Comparative International Development 25 (1), 126-157.

Solt, F., 2009. Standardising the world income inequality database. Social Science Quarterly 90 (2), 231-242. SWIID Version 4.0, September 2013.

Teorell, J., 2010. Determinants of Democratization: Explaining Regime Change in the World, 1972-2006. Cambridge University Press, New York.

\section{Tables}

Table 1: Distribution of Gini coefficients by political institutions, yearly data

\begin{tabular}{|c|c|c|c|c|c|c|}
\hline & \multicolumn{3}{|c|}{ Non-democracies } & \multicolumn{3}{|c|}{ Democracies } \\
\hline & Income range & 10th p. Gini & 90th p. Gini & Income range & 10th p. Gini & 90th p. Gini \\
\hline 0 - 25th p. income p.c. & $\min -1067.55$ & 30.30 & 59.03 & $\min -4365.62$ & 33.13 & 54.02 \\
\hline 25th - 50th p. income p.c. & $1067.55-2046.39$ & 33.45 & 54.35 & $4365.62-10321.44$ & 32.55 & 54.85 \\
\hline 50th - 75th p. income p.c. & $2046.39-4890.67$ & 31.07 & 51.38 & $10321.44-21952.59$ & 24.13 & 37.83 \\
\hline 75th - 100th p. income p.c. & $4890.671-\max$ & 30.47 & 50.55 & $21952.59-\max$ & 22.90 & 34.01 \\
\hline
\end{tabular}


Table 2: Summary for baseline sample, yearly data

\begin{tabular}{|c|c|c|c|c|c|c|}
\hline & \multicolumn{3}{|c|}{ Non-democracies } & \multicolumn{3}{|c|}{ Democracies } \\
\hline & Mean & Std.Dev. & Obs. & Mean & Std.Dev. & Obs. \\
\hline Gini coefficient, net income & 41.23 & 9.40 & 1327 & 37.20 & 10.48 & 2525 \\
\hline Gini coefficient, gross income & 44.85 & 10.20 & 1276 & 45.39 & 7.77 & 2521 \\
\hline Real GDP per capita, chain series & 3890.25 & 5278.98 & 1327 & 14031.77 & 11814.53 & 2525 \\
\hline Share of region democracy & 0.25 & 0.25 & 1327 & 0.73 & 0.30 & 2467 \\
\hline Inequality instrument & 0.05 & 0.14 & 1327 & 0.12 & 0.21 & 2525 \\
\hline
\end{tabular}
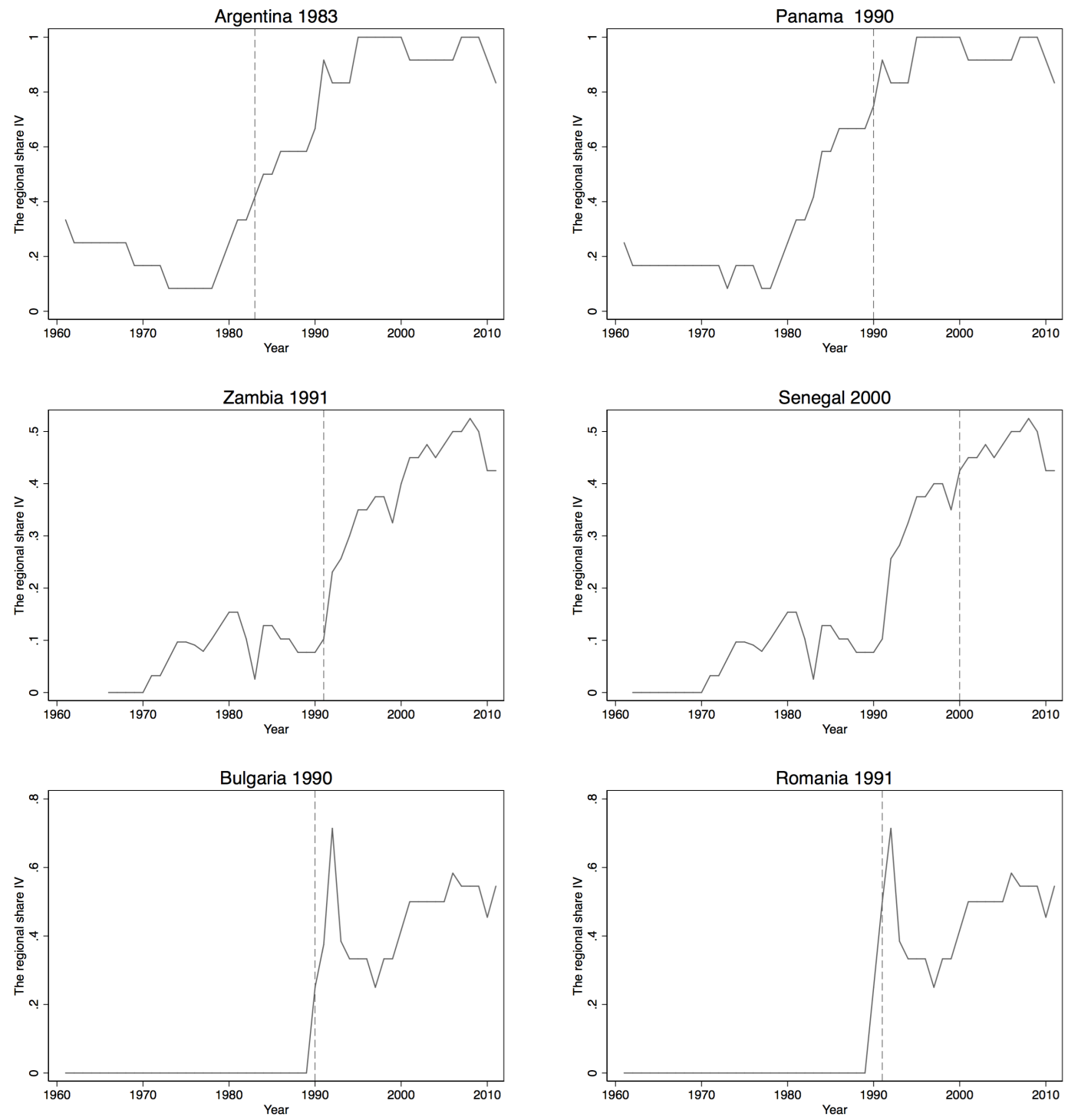

Figure 5: Democratic switches and the regional share instrument. 


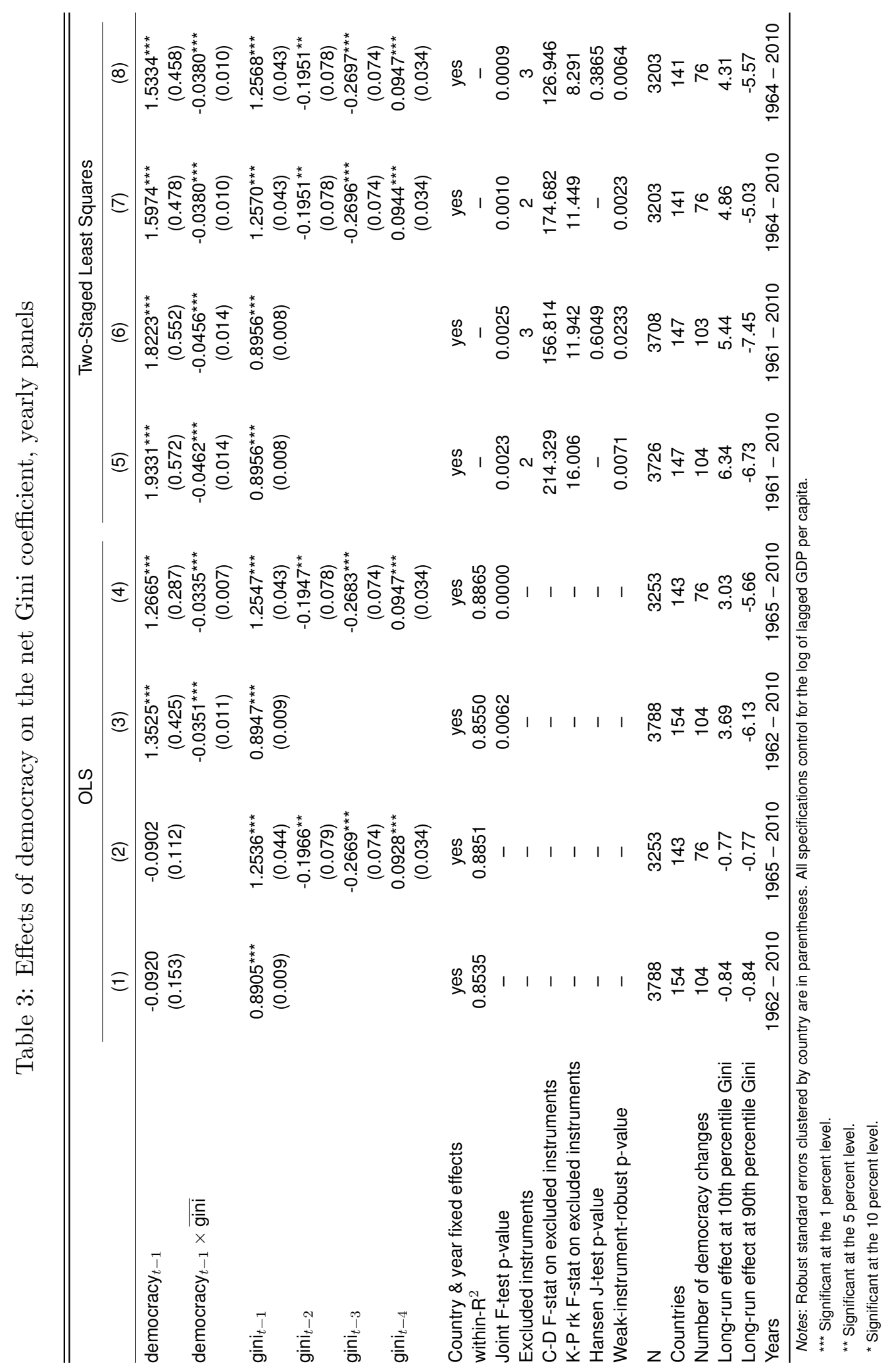




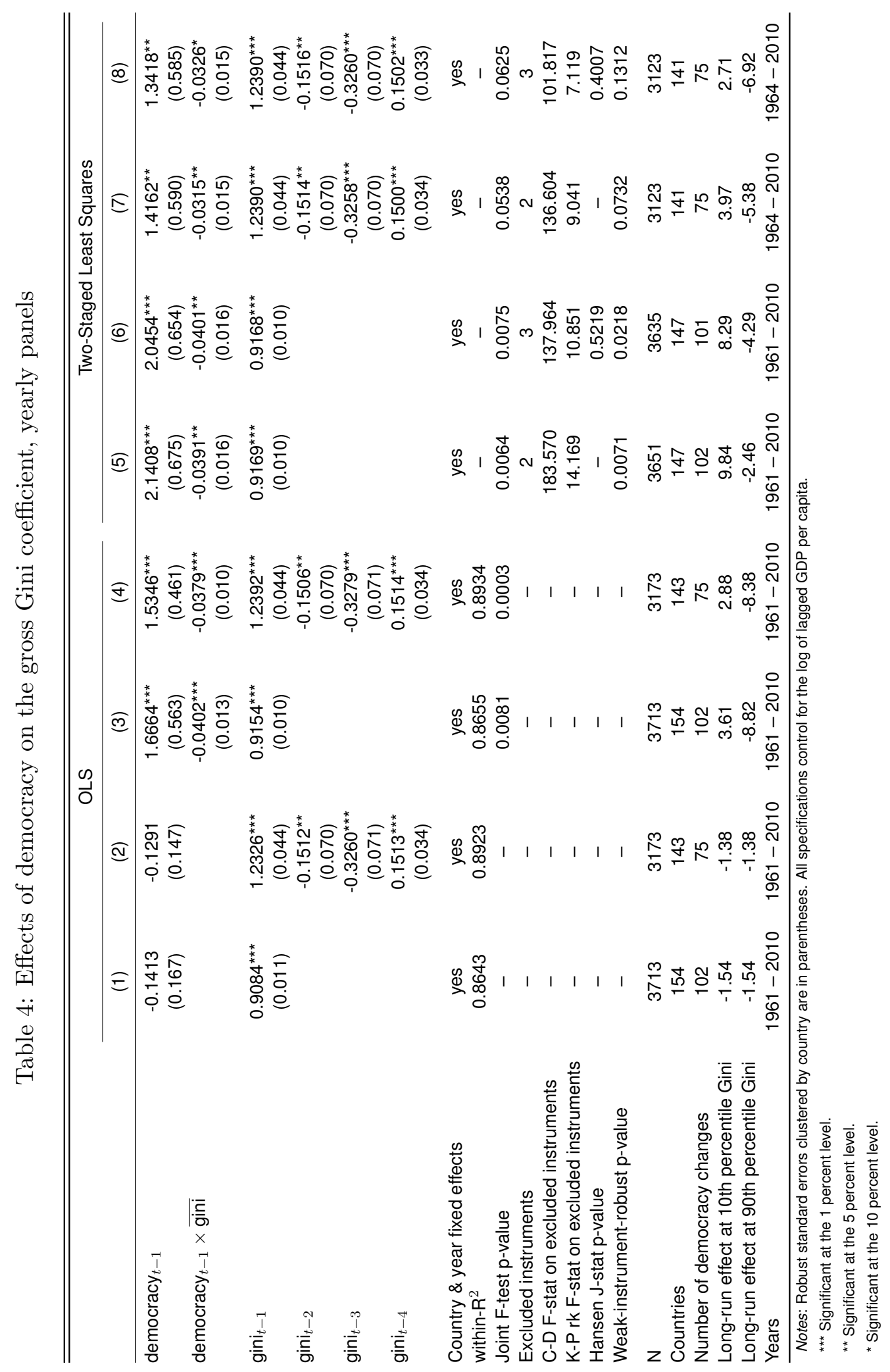




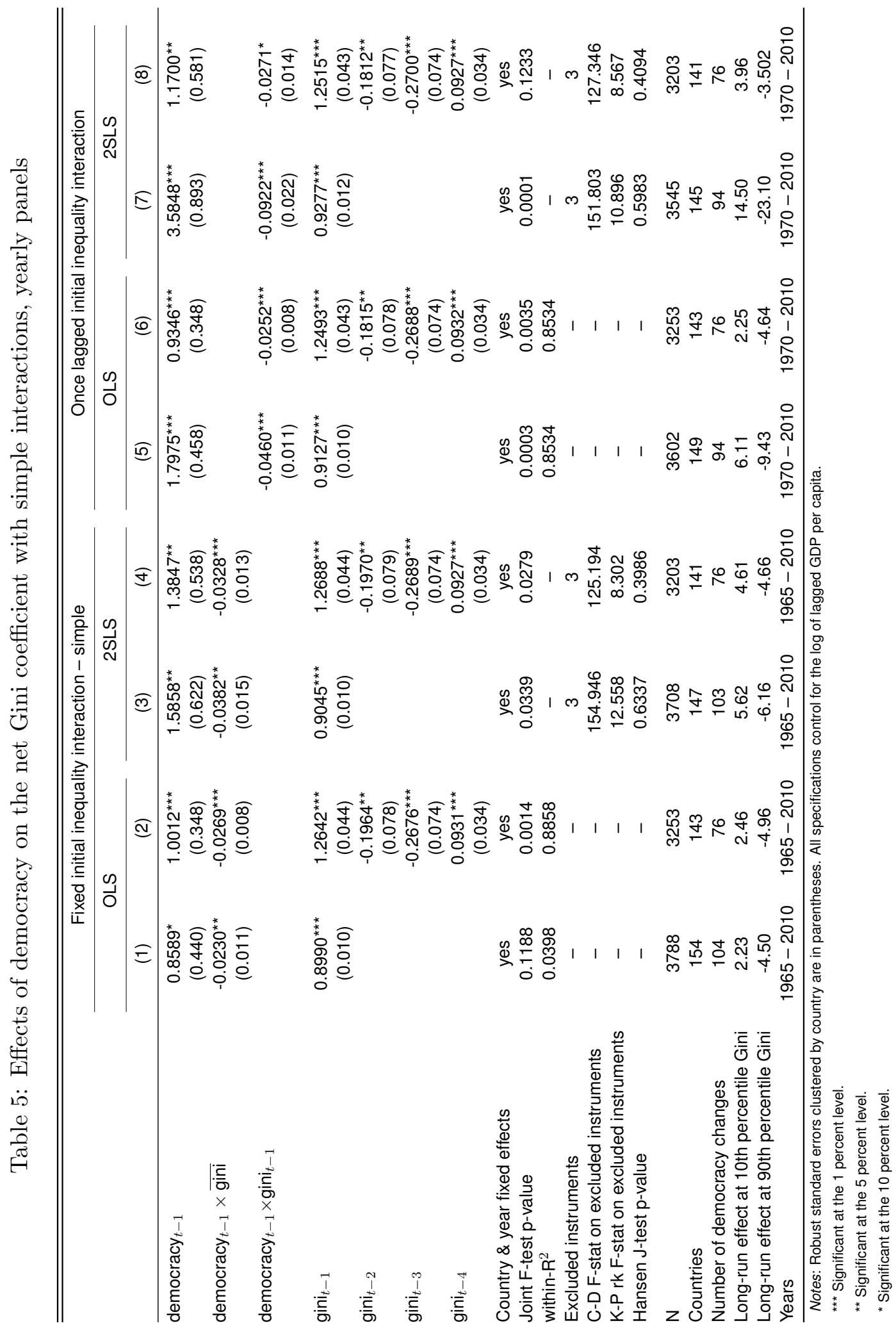




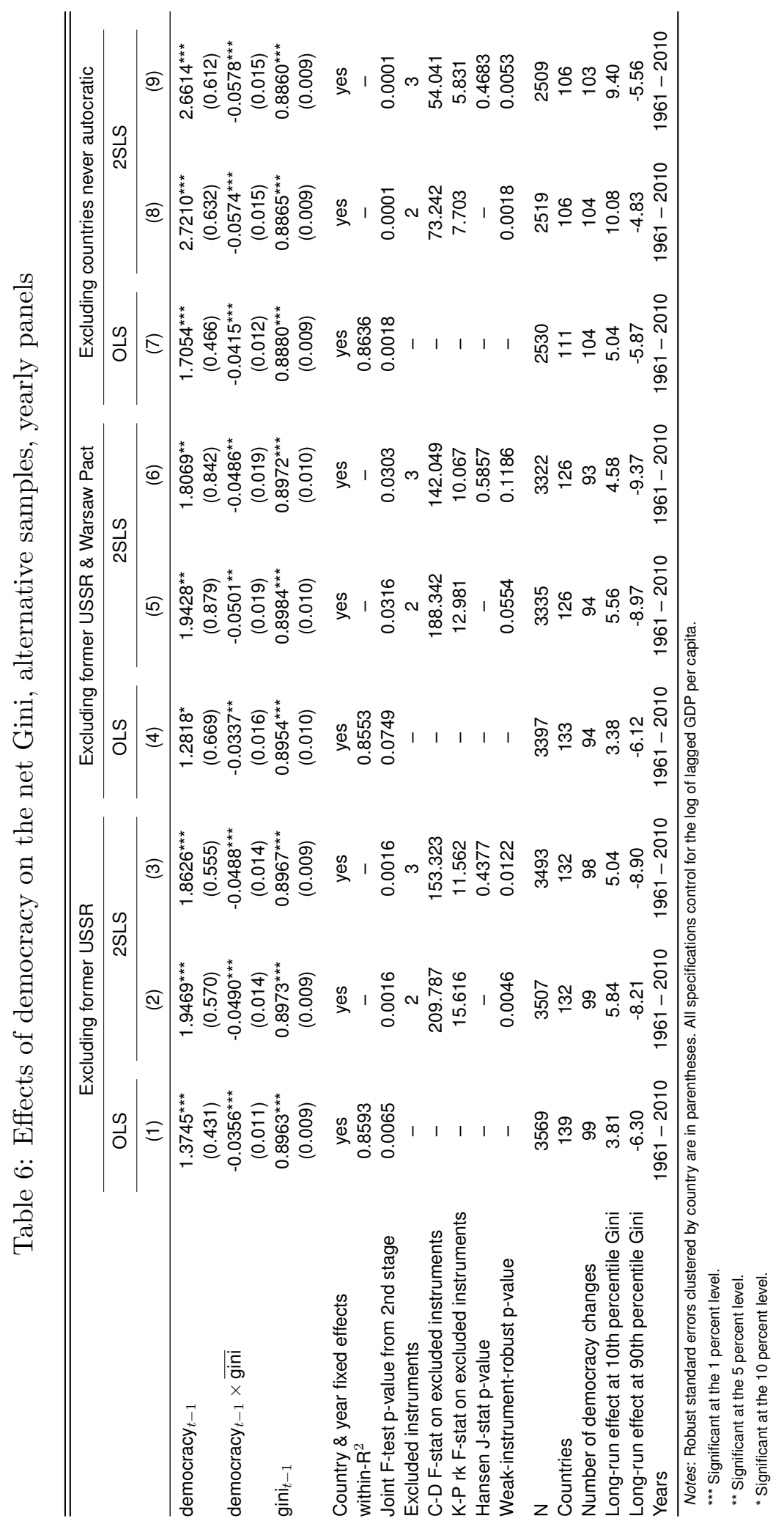




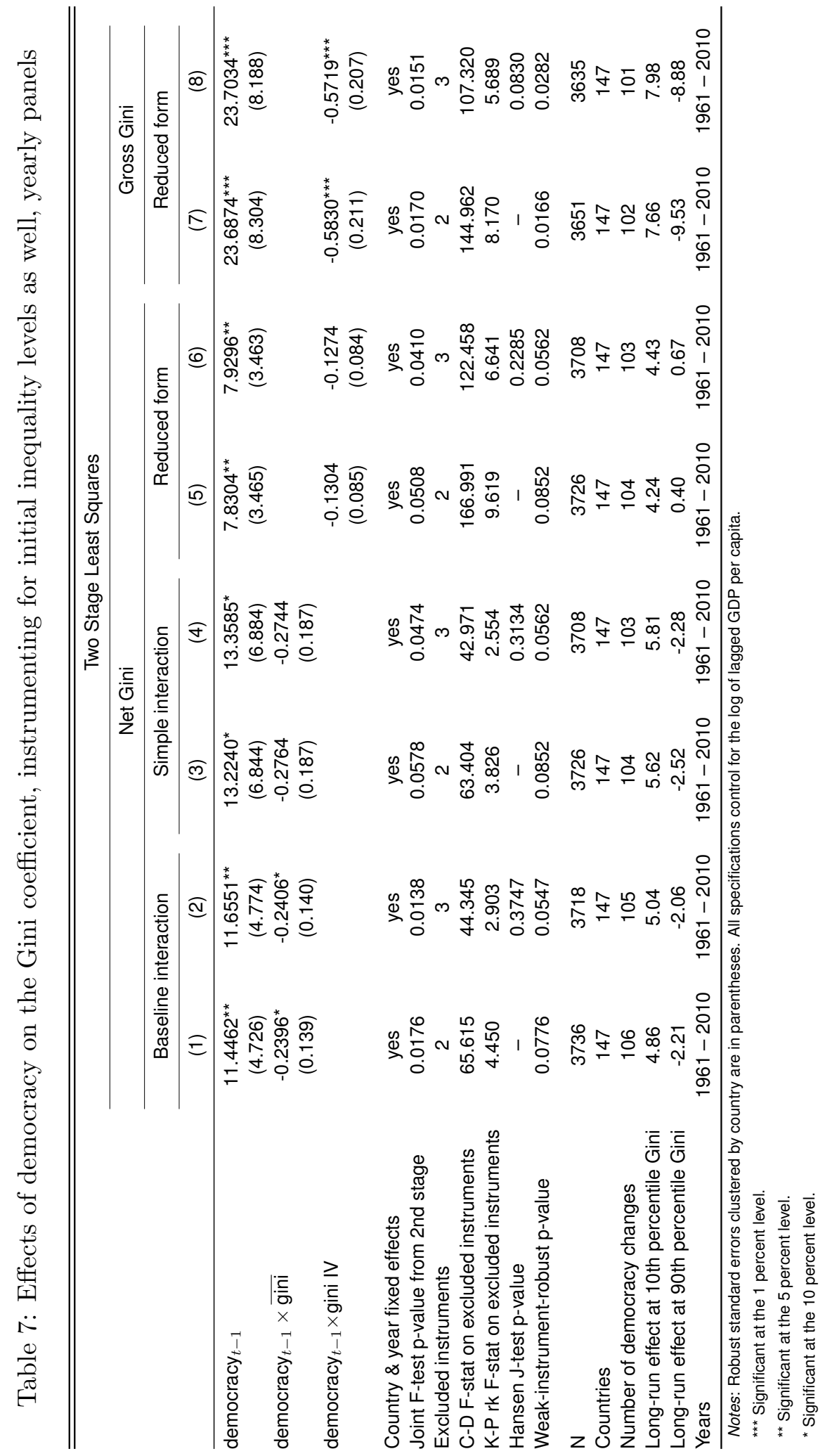




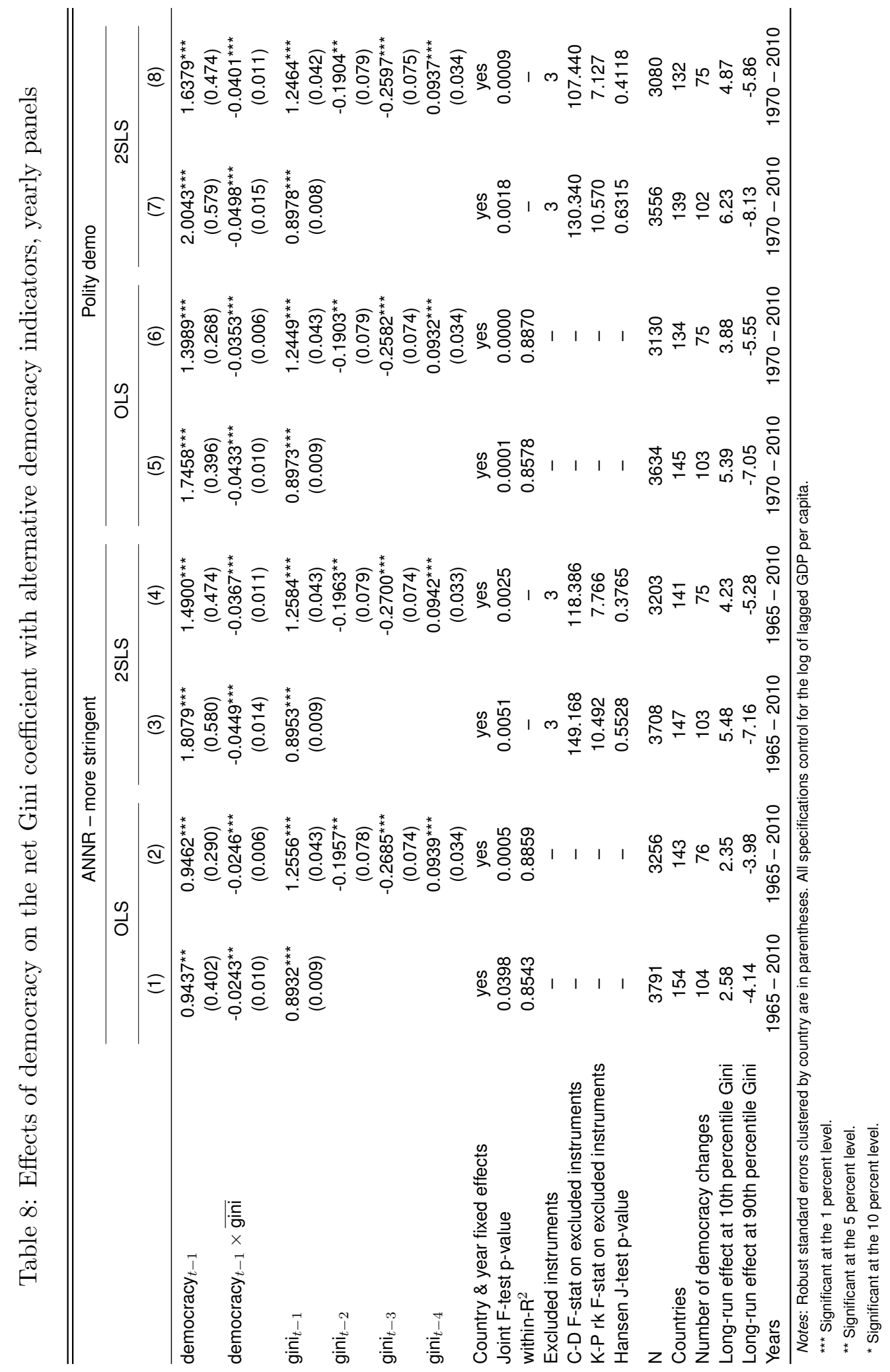




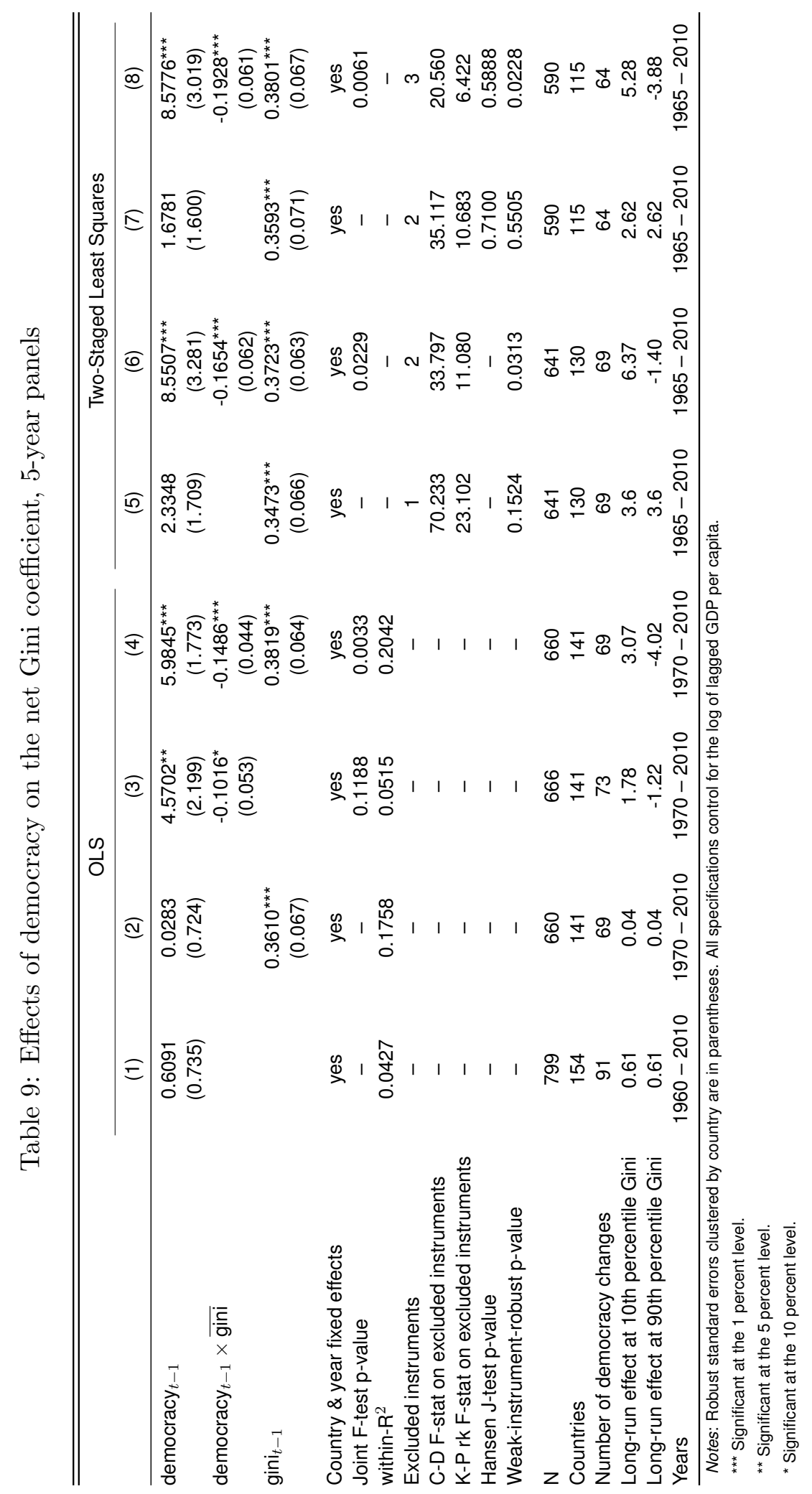




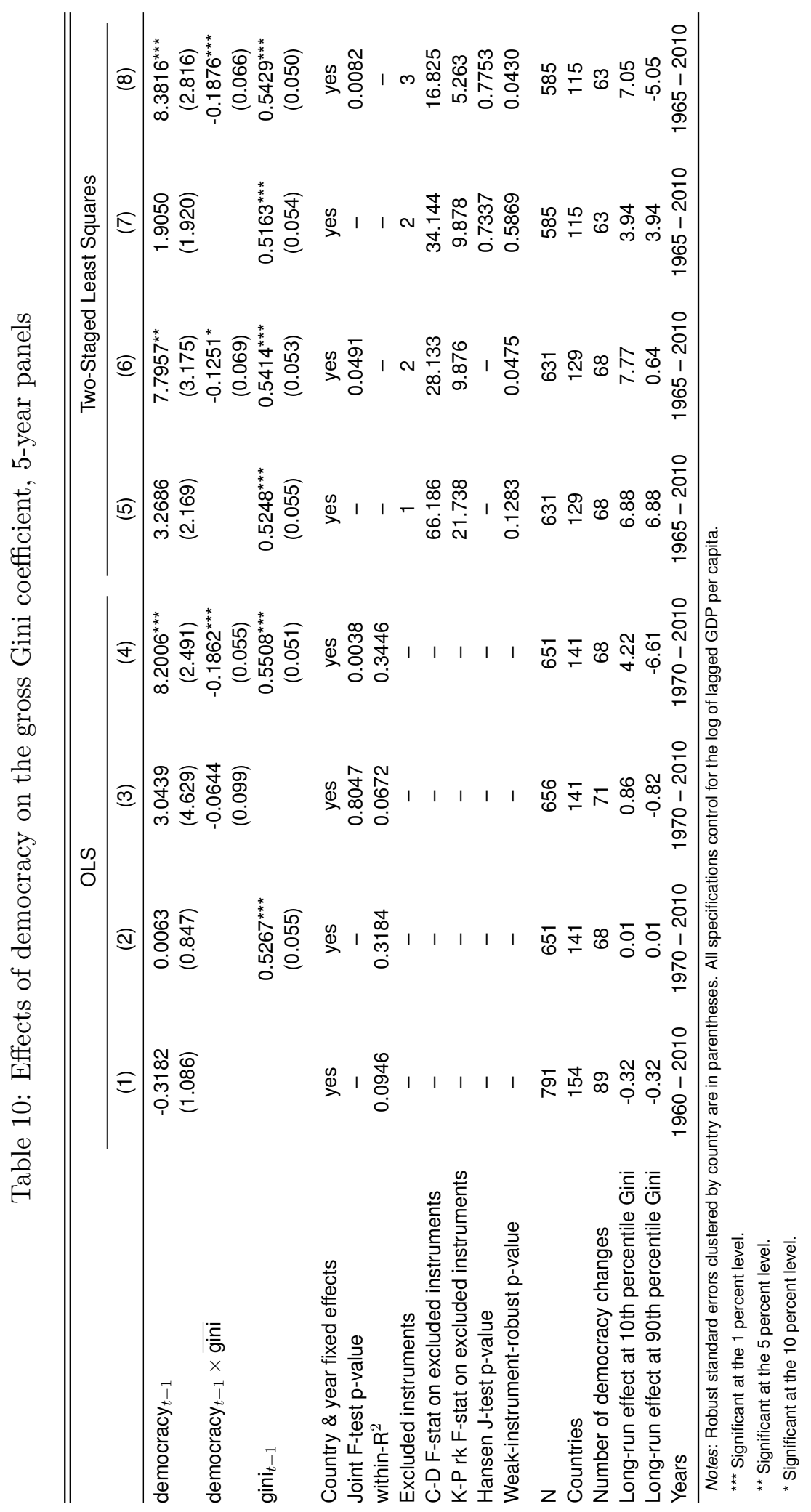




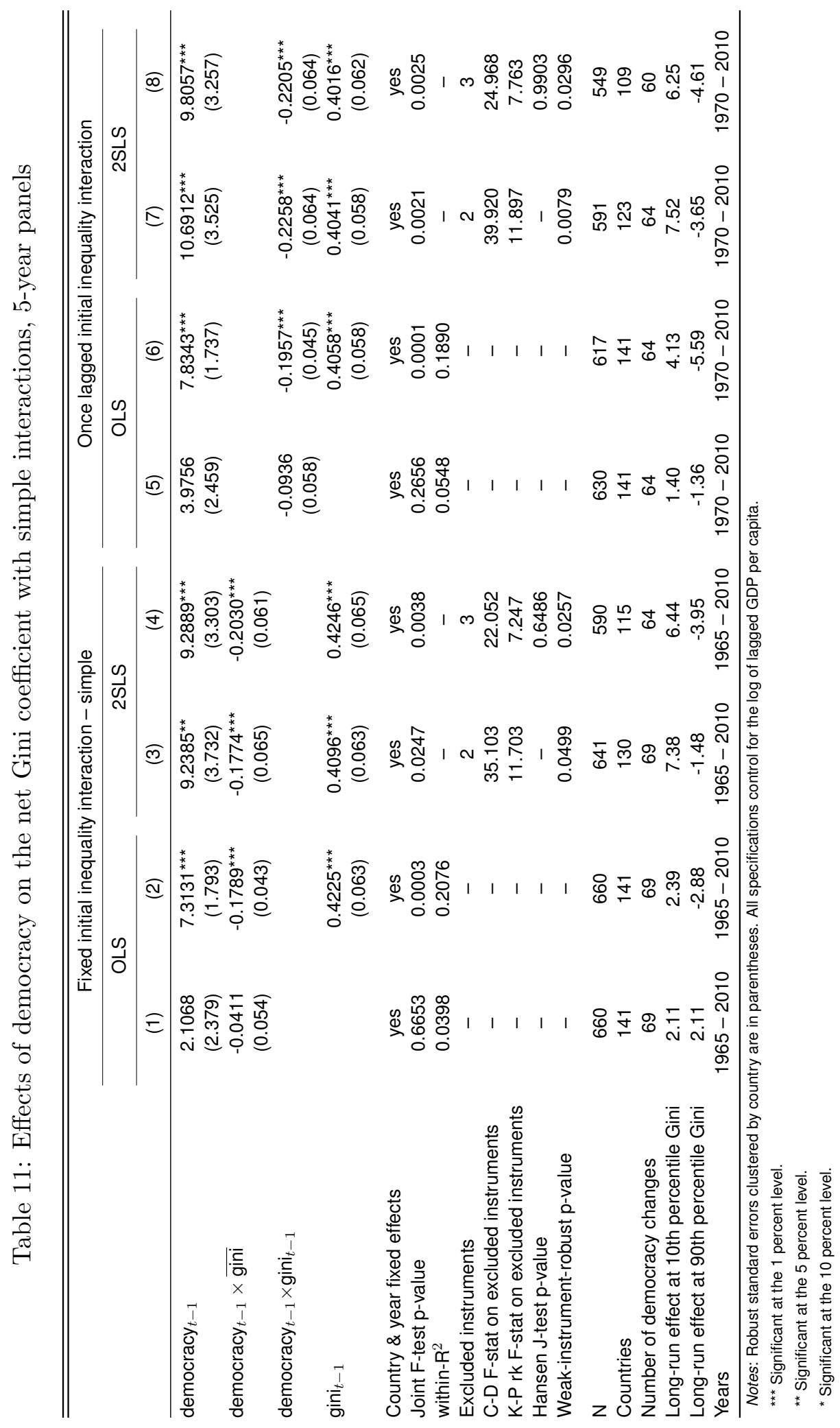




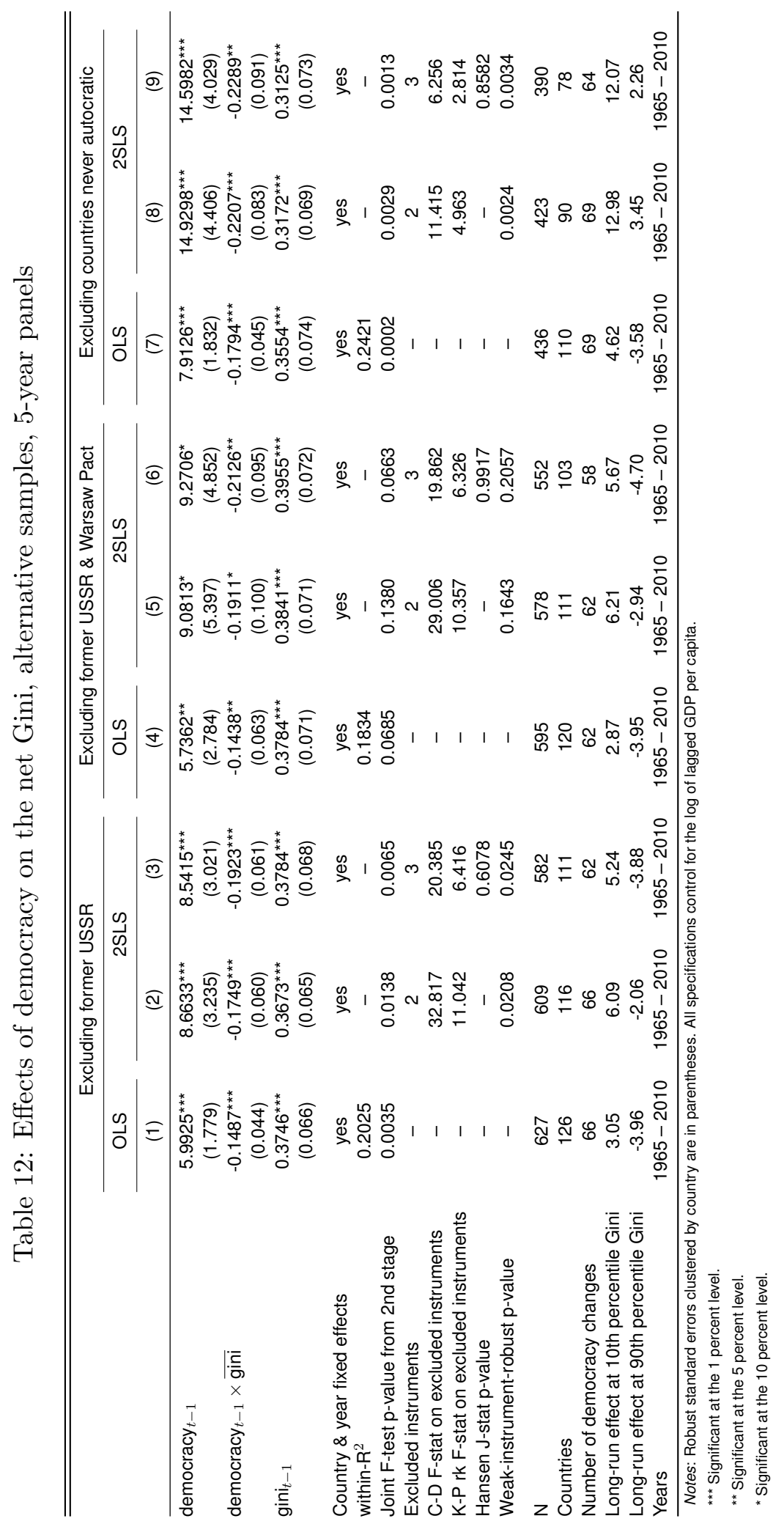




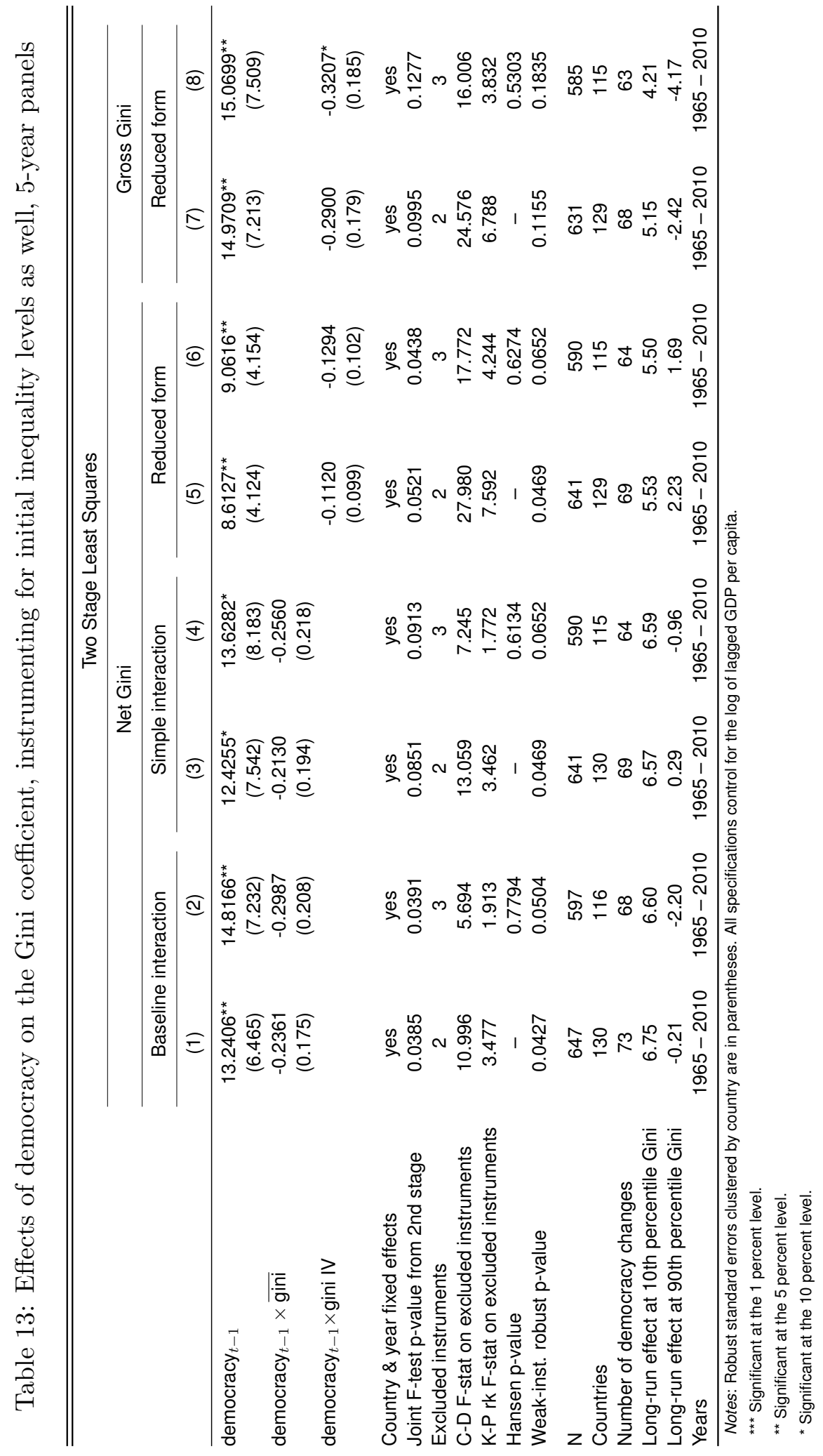


Table 14: Effects of democracy on the the Gini coefficient, GMM regressions

\begin{tabular}{|c|c|c|c|c|}
\hline & \multicolumn{2}{|c|}{ Yearly panels } & \multicolumn{2}{|c|}{ 5-year panels } \\
\hline & $\begin{array}{l}\text { Net Gini } \\
(1)\end{array}$ & $\begin{array}{c}\text { Gross Gini } \\
\text { (2) }\end{array}$ & $\begin{array}{l}\text { Net Gini } \\
\text { (3) }\end{array}$ & $\begin{array}{c}\text { Gross Gini } \\
\text { (4) }\end{array}$ \\
\hline democracy $_{t-1}$ & $\begin{array}{c}3.0915^{\star \star *} \\
(0.840)\end{array}$ & $\begin{array}{c}2.0718^{*} \\
(1.074)\end{array}$ & $\begin{array}{c}7.3395^{\star *} \\
(3.395)\end{array}$ & $\begin{array}{l}6.1339^{*} \\
(3.344)\end{array}$ \\
\hline democracy $_{t-1} \times \overline{\text { gini }}$ & $\begin{array}{c}-0.0731^{* * *} \\
(0.020)\end{array}$ & $\begin{array}{c}-0.0403^{\star} \\
(0.022)\end{array}$ & $\begin{array}{c}-0.1751^{* *} \\
(0.084)\end{array}$ & $\begin{array}{l}-0.1291^{*} \\
(0.076)\end{array}$ \\
\hline $\operatorname{gini}_{t-1}$ & $\begin{array}{c}0.9662^{\star \star \star} \\
(0.018)\end{array}$ & $\begin{array}{c}0.9738^{\star * *} \\
(0.015)\end{array}$ & $\begin{array}{c}0.5896^{\star * *} \\
(0.075)\end{array}$ & $\begin{array}{c}0.7136^{* * *} \\
(0.056)\end{array}$ \\
\hline Year fixed effects & yes & yes & yes & yes \\
\hline Joint F-test p-value & 0.0013 & 0.1529 & 0.0977 & 0.1893 \\
\hline Number of instruments & 272 & 272 & 220 & 219 \\
\hline$A R(2) p$-value & 0.264 & 0.066 & 0.749 & 0.898 \\
\hline $\mathrm{N}$ & 3788 & 3713 & 660 & 651 \\
\hline Countries & 154 & 154 & 141 & 141 \\
\hline Number of democracy changes & 104 & 102 & 69 & 68 \\
\hline L-R effect at 10 th percentile Gini & 32.01 & 26.98 & 6.15 & 6.16 \\
\hline L-R effect at 90th percentile Gini & -31.84 & -13.26 & -6.43 & -5.61 \\
\hline
\end{tabular}

Notes: Robust standard errors clustered by country are in parentheses. All specifications control for the log of lagged GDP per capita. Data covers the period $1961-2010$.

*** Significant at the 1 percent level.

** Significant at the 5 percent level.

* Significant at the 10 percent level. 
Table 15: Democratic Switches in our Baseline Sample

\begin{tabular}{|c|c|c|c|c|c|}
\hline Year & Country & Initial net Gini & Country & Year & Initial net Gini \\
\hline 1997 & Albania & 28.09 & 1991 & Madagascar & 46.87 \\
\hline 1983 & Argentina & 40.03 & 1994 & Malawi & 58.69 \\
\hline 1991 & Bangladesh & 28.32 & 1972 & Malaysia & 50.56 \\
\hline 2009 & Bangladesh & 37.68 & 1983 & Malaysia & 43.86 \\
\hline 1998 & Armenia & 41.19 & 1992 & Mali & 36.02 \\
\hline 1983 & Botswana & 53.53 & 1994 & Mexico & 46.18 \\
\hline 1985 & Brazil & 55.18 & 1990 & Nepal & 28.06 \\
\hline 1990 & Bulgaria & 22.68 & 1999 & Niger & 42.14 \\
\hline 2003 & Burundi & 38.38 & 1999 & Nigeria & 52.27 \\
\hline 1991 & Cape Verde & 40.11 & 1988 & Pakistan & 33.61 \\
\hline 1993 & Central African Rep. & 58.69 & 1990 & Panama & 47.26 \\
\hline 1983 & Sri Lanka & 45.02 & 1993 & Peru & 55.14 \\
\hline 1989 & Chile & 51.17 & 1986 & Philippines & 45.16 \\
\hline 1992 & Taiwan & 26.90 & 1989 & Poland & 24.91 \\
\hline 2002 & Comoros & 50.78 & 1994 & Guinea-Bissau & 51.56 \\
\hline 1999 & Croatia & 31.12 & 1999 & Guinea-Bissau & 48.27 \\
\hline 1983 & EI Salvador & 46.95 & 2005 & Guinea-Bissau & 38.97 \\
\hline 1983 & Fiji & 39.13 & 1991 & Romania & 19.69 \\
\hline 1990 & Fiji & 41.36 & 2000 & Senegal & 40.35 \\
\hline 1999 & Djibouti & 38.12 & 1996 & Sierra Leone & 61.41 \\
\hline 1996 & Ghana & 38.56 & 2001 & Sierra Leone & 54.52 \\
\hline 1974 & Greece & 33.67 & 1973 & South Africa & 65.07 \\
\hline 1986 & Guatemala & 43.60 & 1983 & South Africa & 64.91 \\
\hline 1992 & Guyana & 42.12 & 1978 & Zimbabwe & 55.30 \\
\hline 1990 & Haiti & 53.77 & 1976 & Spain & 30.36 \\
\hline 1994 & Haiti & 53.80 & 1974 & Thailand & 49.07 \\
\hline 1989 & Hungary & 21.54 & 1978 & Thailand & 47.08 \\
\hline 1999 & Indonesia & 36.73 & 1992 & Thailand & 49.66 \\
\hline 2000 & Cote d'Ivoire & 37.01 & 1973 & Turkey & 52.96 \\
\hline 2002 & Kenya & 47.40 & 1983 & Turkey & 50.09 \\
\hline 1987 & Korea, South & 35.92 & 1985 & Uruguay & 40.50 \\
\hline 2005 & Kyrgyzstan & 35.65 & 1991 & Zambia & 61.29 \\
\hline 2005 & Lebanon & 43.48 & & & \\
\hline 1993 & Lesotho & 59.06 & & & \\
\hline 1999 & Lesotho & 59.01 & & & \\
\hline
\end{tabular}

Notes: Democratic switches are coded as in the baseline specification. 